Portland State University

PDXScholar

$1-18-1974$

\title{
Optimization of single- and double-flash cycles and space heating systems in geothermal engineering
}

Talal Hussein Hassoun

Portland State University

Follow this and additional works at: https://pdxscholar.library.pdx.edu/open_access_etds

Part of the Geotechnical Engineering Commons

Let us know how access to this document benefits you.

\section{Recommended Citation}

Hassoun, Talal Hussein, "Optimization of single- and double-flash cycles and space heating systems in geothermal engineering" (1974). Dissertations and Theses. Paper 1976.

https://doi.org/10.15760/etd.1975

This Thesis is brought to you for free and open access. It has been accepted for inclusion in Dissertations and Theses by an authorized administrator of PDXScholar. Please contact us if we can make this document more accessible: pdxscholar@pdx.edu. 
AN ABSTRACT OF THE THESIS OF Talal Hussein Hassoun for the Master of Science in Applied Science presented January 18, 1974.

Title: Optimization of Single- and Double-Flash Cycles and Space Heating Systems in Geothermal Engineering

APPROVED BY MEMBERS OF THE THESIS COMMITTEE:

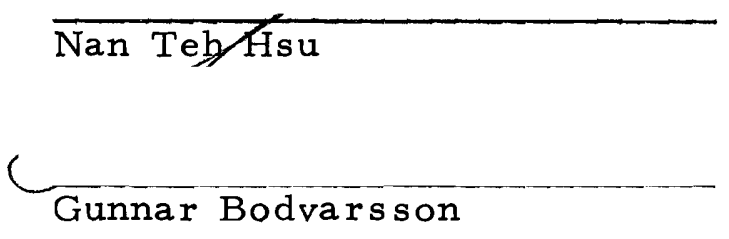

Georgetisongas

Two different problems of optimization in the utilization of geothermal energy are presented: First, the thermodynamic optimization for a geothermal power plant using a single- or double-flash process is considered; in this analysis, the optimum flash temperature giving the maximum power output is determined. Second, an economic optimization for space heating systems using geothermal energy is developed to obtain operating conditions for which the total (capital and operating) cost is a minimum.

Both graphical and analytical methods are used in the thermodynamic optimization to determine the optimum flash temperature. The graphical method is based on thermodynamic data 
provided by an i-s (enthalpy-entropy) diagram for water and steam. In the analytical method, first and second order approximations (first and second degree polynomial approximations), are used for the functions which express enthalpy differences in terms of flash temperature.

Numberical results are provided by computer programs developed for the analytical method. These results cover the temperature range normally encountered in practice. In the case of the single-flash cycle, results from both the graphical and analytical method using the first order approximation indicate the same optimum flash temperature; however, the correction factor resulting from the second order approximation improves the value of the temperature by a correction of about $-2^{\circ} \mathrm{C}$. Optimum flash temperatures for the double-flash cycle are similarly determined using the analytical method with a first order approximation.

In the economic optimization of space heating systems, the analysis is made on the basis of the annual total cost per unit area of wall surface. It takes into account the cost of the geothermal fluid, cost of wall insulation, and heat exchanger cost. For a specific case where the inlet temperature to the heat exchanger is at $100^{\circ} \mathrm{C}$ and the outlet temperature at $28^{\circ} \mathrm{C}$, the minimum annual cost to maintain a space at $20^{\circ} \mathrm{C}$ with an outside temperature of 
$-10^{\circ} \mathrm{C}$ is given at $\$ 0.0257$ per square meter of wall area while the optimum thickness for the wall insulation is 0.126 meter. Additional improvement in the optimization of flash temperature can be made by using a second order approximation method for the double-flash power cycle. 


\title{
OP TIMIZATION OF SINGLE- AND DOUBLE-FLASH \\ CYCLES AND SPACE HEATING SYSTEMS \\ IN GEOTHERMAL ENGINEERING
}

\author{
by \\ TALAL HUSSEIN HASSOUN
}

\begin{abstract}
A thesis submitted in partial fulfillment of the requirements for the degree of
\end{abstract}

\begin{abstract}
MASTER OF SCIENCE
in

APPLIED SCIENCE
\end{abstract}

Portland State University

1974 
I TO THE OFFICE OF GRADUATE STUDIES AND RESEARCH: The members of the Committee approve the thesis Talal Hussein Hassoun presented January, 18, 1974.

APPROVED:

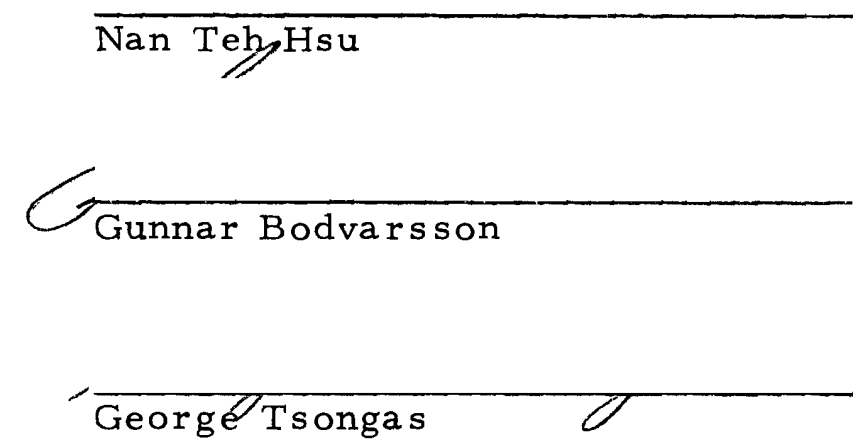

Nan Teh Hsu, Head, Department of
Applief Science and Engineering

David T. Clark, Dean of Graduate Studies and Research 


\section{ACKNOW LEDGEMENTS}

The author gratefully acknowledges indebtedness to Professor Bodvarsson for his suggestion of the problem, criticisms, and suggestions during the course of the research, and especially his giving of unlimited time and effort during the writing of this thesis.

The author wishes to express his gratitude to Dr. N.T. Hsu for his advice, helpful discussions, and reviewing the thesis and especially for providing the computer time. I would also like to express my appreciation to Dr. George Tsongas for making many constructive comments.

Discussions with various engineers and geologists were of great help to me; I want to mention in particular Mr. David Ebsen, Mr.Russ Mudge, and Richard G. Bowen.

The author wishes to thank Mrs. Janijo Weidner for the excellent and efficient typing of this thesis. I am especially indebted to my wife for her encouragement, understanding, and unfailing patience. 
TABLE OF CONTENTS

PAGE

ACKNOW LEDGEMENTS ................ iii

LIST OF TABLES $\ldots \ldots \ldots \ldots \ldots \ldots \ldots \ldots \ldots \ldots \ldots \ldots \ldots \ldots$

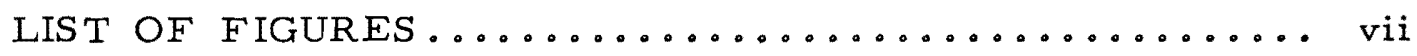

CHAPTER

I INTRODUCTION $\ldots \ldots \ldots \ldots \ldots \ldots \ldots \ldots \ldots$

II GEOTHERMAL RESOURCES.......... 4

Classification of Geothermal Reservoirs.... 9

Liquid-Phase Reservoir............ 10

Gas-Liquid Reservoir............ 12

Hot-Rock-Dry Reservoir ........... 14

MAGMAMAX Power Plant .......... 16

III POWER CYCLES FOR LIQUID-PHASE

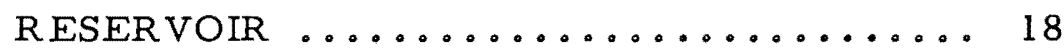

Single-Flash Power Cycles .......... 18

Double-Flash Power Cycles .......... 24

IV THERMODYNAMIC OPTIMIZATION OF

SINGLE-AND DOUBLE-FLASH

POWER CYCLES ................. 31

Graphical Method: Single-Flash

Processes .................. 32

Analytical Method: First Order

Approximation for Single-Flash

Processes .................. 38 
Analytical Method: Second Order Approximation for SingleFlash Processes................40

Numerical Calculations Leading to the Optimum Flash Temperature for Single-Flash Power Cycles ......... 44

Analytical Method: First Order

Approximation for Double-Flash Processes .................... 48 Numerical Calculations Leading to the Optimum Flash Temperatures for Double-Flash Power Cycles ......... 52

V ECONOMIC OPTIMIZATION FOR A GEOTHERMAL HEATING SYSTEM ... 56

Geothermal Heating System ........57

System Optimization .............59

VI CONCLUSIONS AND RECOMMENDATIONS. .67

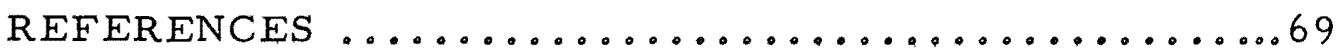

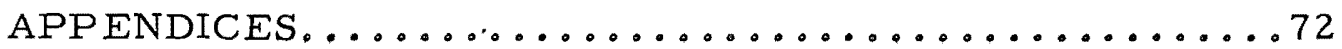




\section{LIST OF TABLES}

TABLE

PAGE

I List of Heat Intensive Industries ........... 6

II Base Temperature in High-Temperature Areas . .. 9

III Geothermal Power Capacity............... 16

IV Performance of Single Flash Cycle: Graphical 37

Method ....................... 


\section{LIST OF FIGURES}

FIGURE

PAGE

1 Liquid-Phase Reservoir................. 10

2 Gas-Liquid Reservoir.................. 12

3 Single Flash Power Cycle .................. 19

4 T-S (temperature-entropy) Diagram of the Single Flash Process .............. 21

5 Double Flash Power Cycle .............. 25

6 T-S (temperature-entropy) Diagram of the Double Flash Process.............. 27

7 Determination of Optimum Flash Temperature for the Case $\mathrm{T}_{\mathrm{o}}=260^{\circ} \mathrm{C}:$ Graphical Method .... 54

8 Determination of Optimum Flash Temperature for the Case $\mathrm{T}_{\mathrm{o}}=260^{\circ} \mathrm{C}$ : Graphical Method.... 55

9 Determination of Optimum Flash Temperature for the Case $\mathrm{T}_{\mathrm{O}}=300^{\circ} \mathrm{C}$ : Graphical Method .... 56

10 Simplified Sketch of a Geothermal Heating System..................... 58

11 Determination of the Optimum Cost for a Geothermal Heating System .......... 66 


\section{-INTRODUCTION}

In geothermal engineering plant design, process evaluation typically consists of both an engineering and economic analysis from which the best conditions of temperature, pressure, rates as well as other variables are determined. Even though economic considerations may ultimately influence the final decision, an optimum operation design based on an engineering evaluation must be obtained first. Thus, the optimum operation design is basically a tool or an initial step in the development of an optimum economic design.

In this study, two different problems of optimization in the utilization of geothermal energy are considered. First, the thermodynamic optimization for a geothermal power plant which uses a single-and a double-flash process in the generation of steam for the turbine is presented; in this case, the optimum flash temperature which gives the maximum power output is determined. Second, an economic optimization for a space heating system using geothermal energy is developed to obtain optimum operating conditions i at which the total (capital and operating) cost is a minimum.

The optimization methods which have been used to obtain these operation conditions are the graphical and analytical methods. 
In the graphical method, values of exergy (capacity to perform work) are plotted against values of flash temperature and the optimum flash temperature is obtained where exergy (see Appendix IV) is a maximum. On the other hand, the analytical method is considered on the basis of first order approximation (first order polynomial approximation) for the cases of single and double-flash cycles, and second order approximation (second order polynomial approximation) for a single-flash power cycle. The approximation is for the function which expresses enthalpy difference in terms of temperature.

This study is organized in five chapters as follows:

Chapter one is an introduction. Chapter two presents a general review on geothermal resources and their importance for the energy market, and also provides a discussion of geothermal reservoirs and their types, including reference so the MAGMAMAX process. In Chapter three the single-and multi-flash processes, with emphasis on single- and double-flash, are discussed. The fourth chapter relates to the core of this research, presenting the methods of optimization, the graphical method and the analytical method on the basis of first and second order approximation techniques for single- and double-flash power cycles. Finally, the last chapter covers an economic optimization for space heating systems. 
The concept of exergy, used in thermodynamic optimization is presented and derived in the Appendix. IV. 


\section{CHAP TER II \\ GEOTHERMAL RESOURCES}

\section{(1)}

stored in the earth. This natural source of energy has been utilized for electric power generation and space heating in a number of locations throughout the world. In Italy, the first power plant was built in 1904 using dry steam; in the U.S.A., power generation began in 1960 utilizing dry steam also; and in New Zealand power generation started in 1950, by using flashed steam from hot water. In Reykjavik, Iceland, about 90,000 people now live in houses heated by geothermal heat.

This new industry has some similarity with the petroleum industry, and as a matter of fact, both industries apply similar procedures of geological and geophysical exploration, well drilling, piping, and concepts of reservoir mechanics. Geothermal resources are considered economically significant when a heat source is concentrated in a manner analogous to the concentration of metals in ore deposits or of oil in commercial reservoirs (26).

Many long-term forecasts of geothermal power generating capacity have been made. The U.S. Geological Survey has stated that the Western United States has a potential generating 
capacity of 15,000 to $30,000 \mathrm{MW}(16)$. The Department of the Interior Panel on Geothermal Energy Resources estimated that geothermal energy could supply as much as 132,000 MW (megawatts) in 1985 and 395,000 MW by the year 2000 (16). Muffler and White (26) pointed out that the world potential geothermal resource is more than 2000 times the heat represented by the total coal resources of the world. Hutchison and Cortez (16) concluded that "one MW of electrical power generated in an oilfired power plant for 30 years at 33 percent thermal efficiency requires the equivalent of 500,000 barrels of crude oil. If the potential generating capacity of the geothermal fields in the Imperial Valley is indeed $20,000 \mathrm{MW}$, it is equivalent to 10 billion barrels of crude oil."

Geothermal resources provide an excellent market for heat intensive industries. Table I indicates that power generation, space heating and desalination are the most promising and highly applicable users of geothermal heat. On the other hand, the rest of the industries on the list show less promise.

It is appropriate in this study of problems in geothermal engineering, to review some of the important conditions and characteristics of the geothermal resources. Muffler (27), defined the geothermal resource base as "all the heat above $15^{\circ} \mathrm{C}$ 
TABLE I

LIST OF HEAT INTENSIVE INDUSTRIES

$\begin{array}{lc} & \begin{array}{c}\text { Heat cost as a } \\ \text { proportion of the }\end{array} \\ \text { Power generation in modern steam plants } & \begin{array}{c}\% \\ \text { finalion cost }\end{array} \\ \text { District hea ting in a cool temperature climate } & 50 \\ \text { Desalination by evaporation } & 40 \\ \text { Heavy water production by distillation } & 20 \\ \text { Alkalies and chlorine industry } & 6 \\ \text { Beet sugar } & 4 \\ \text { Petroleum refining } & 3 \\ \text { Paper and pulp mills } & 3 \\ \text { Synthetic fibers } & 2 \\ \text { Distilling industry } & 1 \\ \text { Canning } & 0.6\end{array}$

The data in this table are obtained from Bodvarsson (6).

in the earth's crust, but only a small portion of this resource considered as a resource". The magnitude of this geothermal resource depends, as a matter of course, on many physical, technological, economical and environmental factors. White, Muffler and Truesdell (32) estimated that the world geothermal 
resource to a depth of 3 kilometer for electrical generation is approximately $2 \times 10^{19}$ calories, which is equivalent to 58,000 megawatts for 50 years.

Certain conditions and requirements must be met before an area can be identified as a geothermal area from which heat can be extracted for economical purposes. According to Bodvarsson, White, Muffler $(6,4,32)$ and others, such a geothermal area is composed of:

1. A heat source - A deep sequence of layers, heated by a magmatic intrusion (dikes, stocks, etc.) which in turn hea ts the overlying porous medium. The heat flux coming from such a heat source determines the economical value of a geothe rmal prospect.

2. A reservoir - A highly permeable hot formation with thickness, porosity and permeability of such an order as to allow the formation and the permanence of a system of convection currents in the water filling the fracture or pore space of the rock. Rocks of all three general types, igneous, sedimentary and metamorphic, may be associated with the geothermal reservoir.

3. A caprock - An impermeable stratum overlying the reservoir. This layer of low permeability prevents the flow of hot water out of the reservoir. 
In view of the discussions above, we can notice that fundamental relations exist between the basic geologic conditions for a geothermal area and the conditions required for an a rea of economic interest. Also, we have to realize that the heat transmitted by the heat source can be extracted if it is transmitted to a fluid, and in this case the fluid is water. Therefore, there must be an adequate amount of water available to extract the energy. The water in a geothermal area is meteoric water (4). In many geothermal areas of the world, the temperature of the reservoir rock is rather uniform below certain depth. This situation is indicative of high permeability, since convection currents in the reservoir tend to equalize the temperature within the reservoir. This observation has led to the concept of the base temperature (6) of a thermal area. A wide range of base temperatures have been observed, and a thermal area which has a base temperature higher than $150^{\circ} \mathrm{C}$ will be denoted as a high-temperature area. Examples of high-base temperature reservoirs are shown in Table II (6). 
TABLE II

BASE TEMPERATURE IN HIGH-

TEMPERA TURE AREAS

\author{
Area \\ Temperature, ${ }^{\circ} \mathrm{C}$ \\ Larderello, Tuscany, Italy \\ 200 \\ Iceland, several areas \\ $200-300$ \\ Salton area, California, U.S.A. \\ 360 \\ Cerro-Prieto, Baja California, Mexico \\ 370 \\ New Zealand, several areas \\ $255-295$ \\ Pauzhetka, U.S.S.R. \\ 195 \\ Geyser, California, U.S.A. \\ 205 \\ Chemical impurities (mainly silica and calcite in thermal \\ water) increase with temperature. At low temperature these \\ materials accumulate and create a problem of deposition of \\ solids in boreholes and equipment (9).
}

\title{
I. CLASSIFICATION OF GEOTHERMAL RESER VOIRS
} Geothermal reservoirs have been classified $(4,32)$ as: 1. Liquid-phase reservoirs .

2. Gas-phase reservoirs.

3. Hot rock - "dry" reservoirs

Among geothermal reservoirs discovered to date, liquid-phase reservoirs are perhaps twenty times as common as gas-phase reservoirs (27). 


\section{LIQUID-PHASE RESER VOIR}

A typical liquid-phase reservoir is shown schematically in Figure 1. This type of reservoir contains water which occupies the effective pore space within the reservoir permeable rock. The recharge water flowing in at the boundaries of the reservoir is heated by the reservoir rocks, expands and moves buoyantly upward through the interconnected pore spaces or fractures. The motive force causing this circulation of water is gravity due to the density difference of cold and hot thermal water. If base temperatures in known areas of this type of reservoir are in the range of $150^{\circ} \mathrm{C}$ to $370^{\circ} \mathrm{C}$, then such a reservoir is denoted as a high-temperature reservoir for power generation (5). Below $150^{\circ} \mathrm{C}$ this type of reservoir is denoted as low-temperature. Steam is produced by boiling as the reservoir water moving up flashes in the boreholes and a mixture of steam and water is produced at the surface.

Chemical impurities such as silica, calcium, potassium, and soluble chloride are usually found in the fluid in a quantity between 1000 to 3000 milligrams per liter (27). Also, the salinity of thermal water from some liquid-phase reservoirs is in the order of 0.1 to 3 percent (27). Geothermal boreholes in the Salton Sea thermal area in California produce a supersaturated brine containing about 320,000 parts per million of 


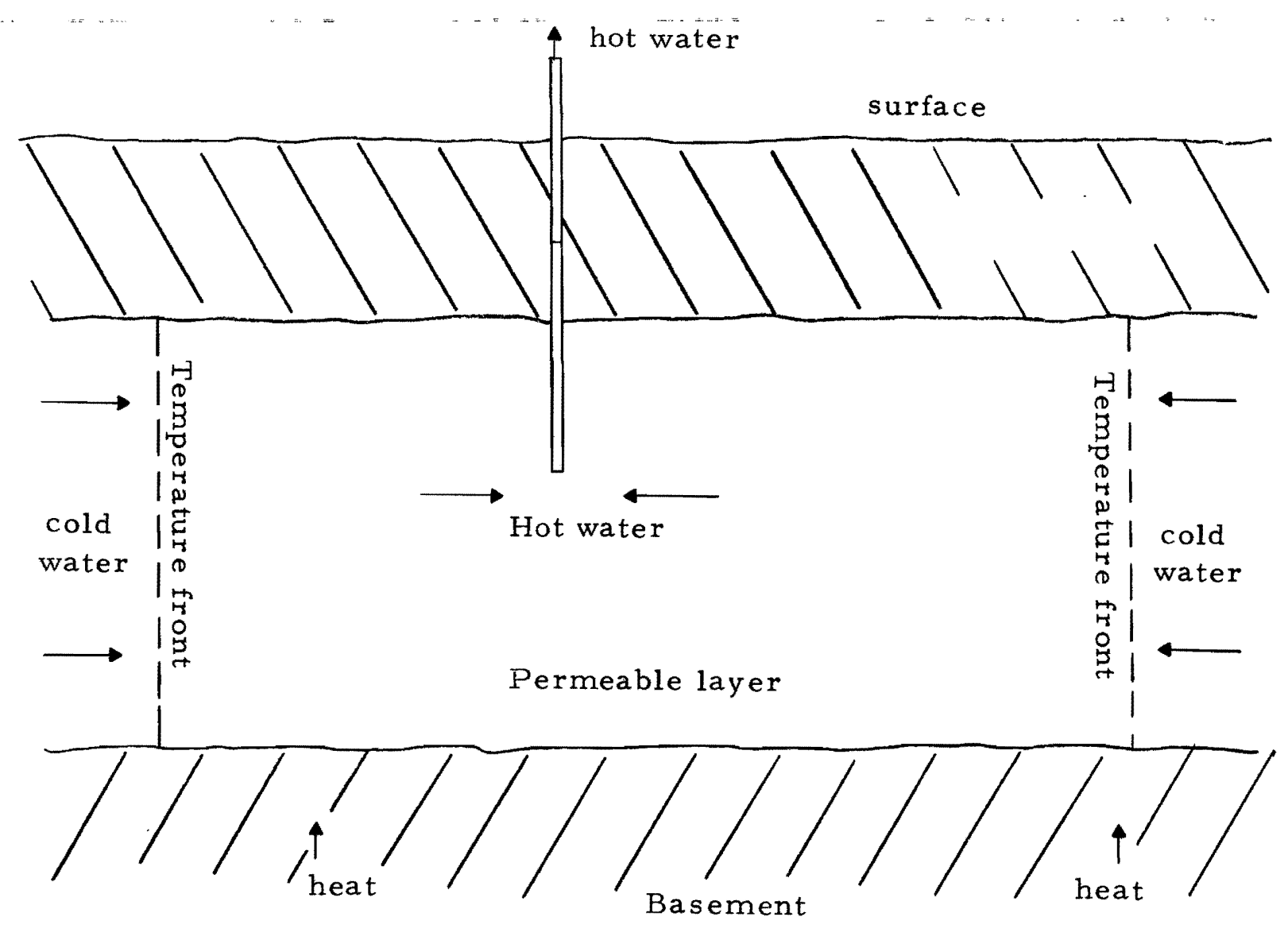

Figure 1. Liquid phase reservoir 
solids, and the salt content can be as high as 20 percent. The brine contains a number of valuable chemicals such as potassium, manganese, lead, zinc, lithium, rubidium, iodine and boron. Various private companies have carried out a considerable amount of research as to the feasibility of extraction of the chemicals (6). As a matter of course, a high concentration of these impurities is not desirable for the reason of environmental hazard.

Examples of major known liquid-phase reservoirs are: Wairaki (generating $160 \mathrm{Mw}$ ) and Broodlands (100 Mw plant proposed) in New Zealand, Cerro Prieto ( $75 \mathrm{Mw}$ plant under construction; $200 \mathrm{Mw}$ plant proposed in Mexico), the Salton Sea field in California, and in Yellowstone geyser basins in the U.S.A. (26).

\section{GAS-PHASE RESERVOIRS}

A gas-phase reservoir, as shown schematically in Figure 2, contains both water and steam at depth. This type of reservoir produces a pure steam phase at the surface with small amounts of non-condensible gases such as $\mathrm{CO}_{2}, \mathrm{NH}_{3}$ and $\mathrm{H}_{2} \mathrm{~S}$. With a decrease in pressure, the evaporation processes of the reservoir fluids proceeds in the reservoir, and the heat of evaporation (latent heat) is provided by the reservoir rock (6). 


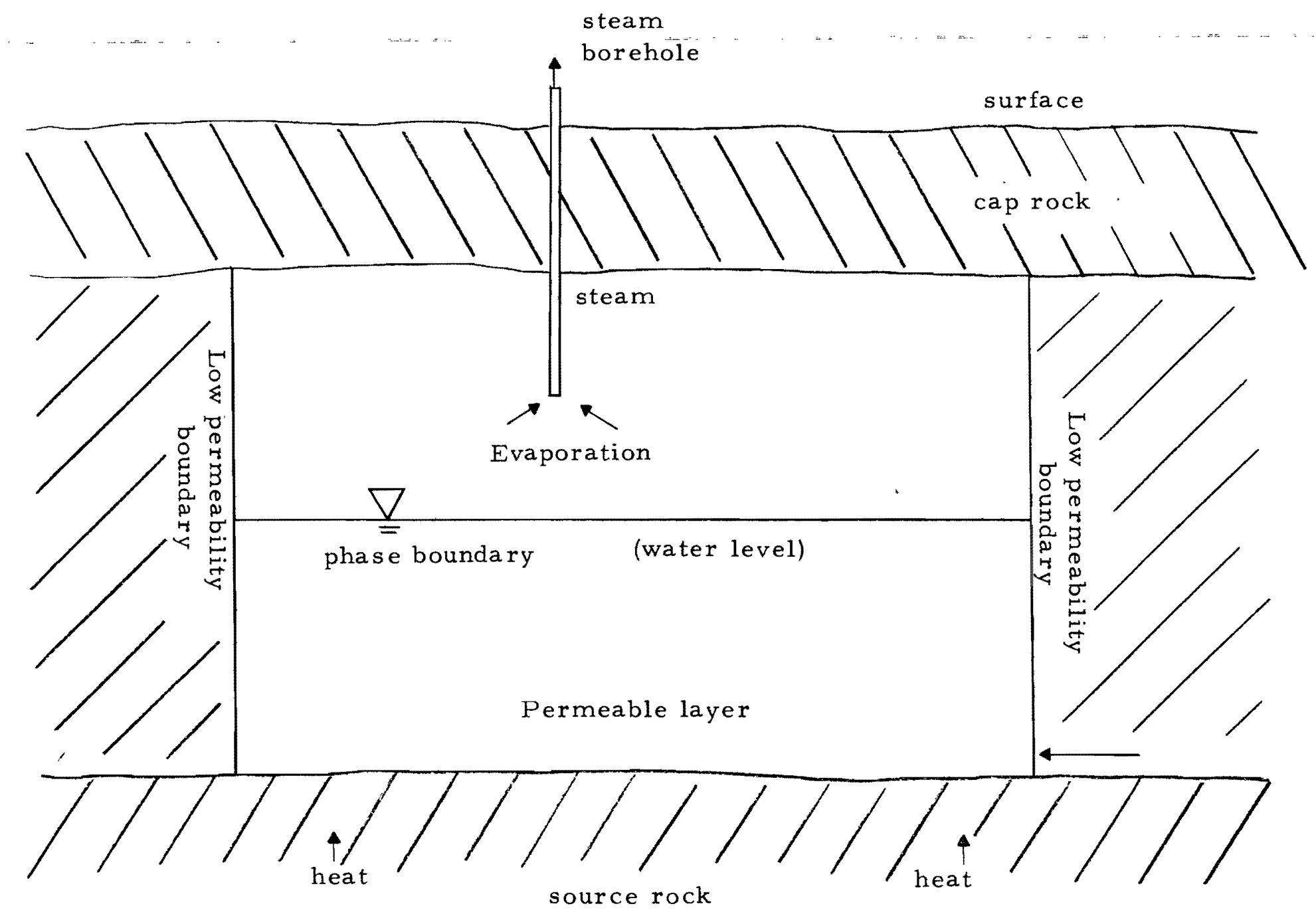

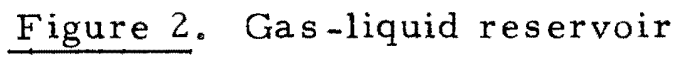


James (19) indicates that gas-phase reservoirs are unlikely to exist at pressures greater than 34 kilograms per square centimeter and temperatures more than $240^{\circ} \mathrm{C}$, due to the thermodynamic properties and flow dynamics of steam and water in a porous media.

Examples of major known geothermal gas-phase reservoirs are: Larderello, Italy; the geysers, California, U.S.A.; and Matsukawa, Japan.

IV. HOT ROCK-DRY GEOTHERMAL RESERVOIRS Another geothermal resource is being considered - hot rock. In the opinion of many experts in this field, this large resource is more difficult to exploit than gas and liquid-phase reservoirs. However, many methods for tapping this dry geothermal deposit have been suggested, such as nuclear explosives and hydrofracturing techniques similar to those employed in petroleum exploration. To be economically fea sible these methods will depend primarily upon how deep the deposits are, since the cost of drilling through hard rock is expected to be highly expensive. However, in the opinion of many experts in this field, the potential of these resources is estimated to be at least ten times the total from gas -phase reservoirs and liquidphase reservoirs. 
From the above conditions it can be as sumed that the available energy in a geothermal reservoir can be economically exploited for power generation if the following characteristics, many of which are independent, are observed:

1. Depth of extraction, which is dependent on the technology and economics assumed.

2. High-temperature reservoir (base temperature).

3. Geometry of permeability, and the specifid yield.

4. Physical state of the fluid in the reservoir (water or steam).

5. Adequate supply of reservoir water.

6. Chemical analys is and composition of the thermal water.

In this study we are concerned only with the liquidphase reservoirs, which are relatively abundant and are producible from a more shallow depth, which would make them particularly useful for space heating, industrial and agricultural purposes (more so than the gas-phase reservoirs). Therefore, the type of power plant used to convert geothermal energy to electrical power and use for space heating depends upon the type of the reservoir and the quality of the geothermal fluid. Electric power generation from geothermal resources worldwide is shown in Table III (16)。 
TABLE III

GEOTHERMAL POWER CAPACITY

(1973)

\begin{tabular}{lc} 
Country & Capacity (Megawatts) \\
\cline { 2 - 2 } Italy & 390 \\
U.S.A. (expected in 1974) & 520 \\
New Zealand & 170 \\
Mexico & 75 \\
Japan & 33 \\
Soviet Union & 6 \\
Iceland & $\frac{3}{1197}$
\end{tabular}

The current worldwide energy crisis has given increased impetus to the large-scale development of geothermal energy. Active exploration and development programs are underway in many parts of the world, including Algeria, Chile, Columbia, Czechoslovakia, El Salvador, Ethiopia, Hungary, Iceland, Italy, Japan, Kenya, Mexico, the Philippines, Russia, Taiwan, Turkey, U.S.A. and Yugoslavia (16).

V. MAGMAMAX POWER PLANT

To overcome a number of problems, some interest has been expressed in the use of secondary working fluids for low- 
temperature liquid-phase geothermal power plants. Because generating power from hot water is different from generating power from steam, theoretical studies have been made on the problem with different proposed cycles.

The MAGMAMAX process (1) has been introduced by Magma Power Company (Los Angeles, California) using isobutane as the second working fluid. Hot water is pumped from the wells and run through a heat exchanger to vaporize isobutane, which expands in a turbine in a separate closed cycle. The isobutane condensate is pumped into the heating and boiling heat exchangers by a turbine-driven centrifugal pump. The condensate hot water is then reinjected back into the reservoir. Due to the high density of the isobutane, the size of the turbine is reduced as compared to ordinary steam turbines of the same output and operating at the same temperatures.

Construction of a $10 \mathrm{Mw}$ pilot plant using the MAGMAMAX process is underway at Brady, Nevada (26). The general principles, cycle and some implications were discussed by Anderson (1).

While use of the MAGMAMAX process for liquid-phase reservoirs is interesting, that process is not amenable to the type of optimization of liquid-phase reservoirs considered in this study. 


\section{CHAPTER III}

POWER CYCLES FOR LIQUID-PHASE RESERVOIR

Broadly speaking, a geothermal power cycle is usually an open thermodynamic cycle, for the purpose of converting a portion of the available energy contained in a fluid phase reservoir into electrical power. The basic procedures of utilizing natural heat sources for power generation are similar to conventional thermal-generating procedures. Major differences are the absence of a boiler in a geothermal plant as well as a lower pressure and temperature of the working fluid. Also, the steam condensate is used for cooling makeup water, rather than recycling for steam production, and there is a need for removal of non-condensible gases from the condenser to maintain a vacuum (23).

In this study, two types of processes will be considered: the single- and multi-flash processes, with emphasis on singleand double-flash power cycles.

\section{SINGLE-FLASH POWER CYCLES}

The single-flash power cycle is the simplest and best known method of extracting energy from a liquid phase reservoir to generate power. Figure 3 illustrates a simple flow 


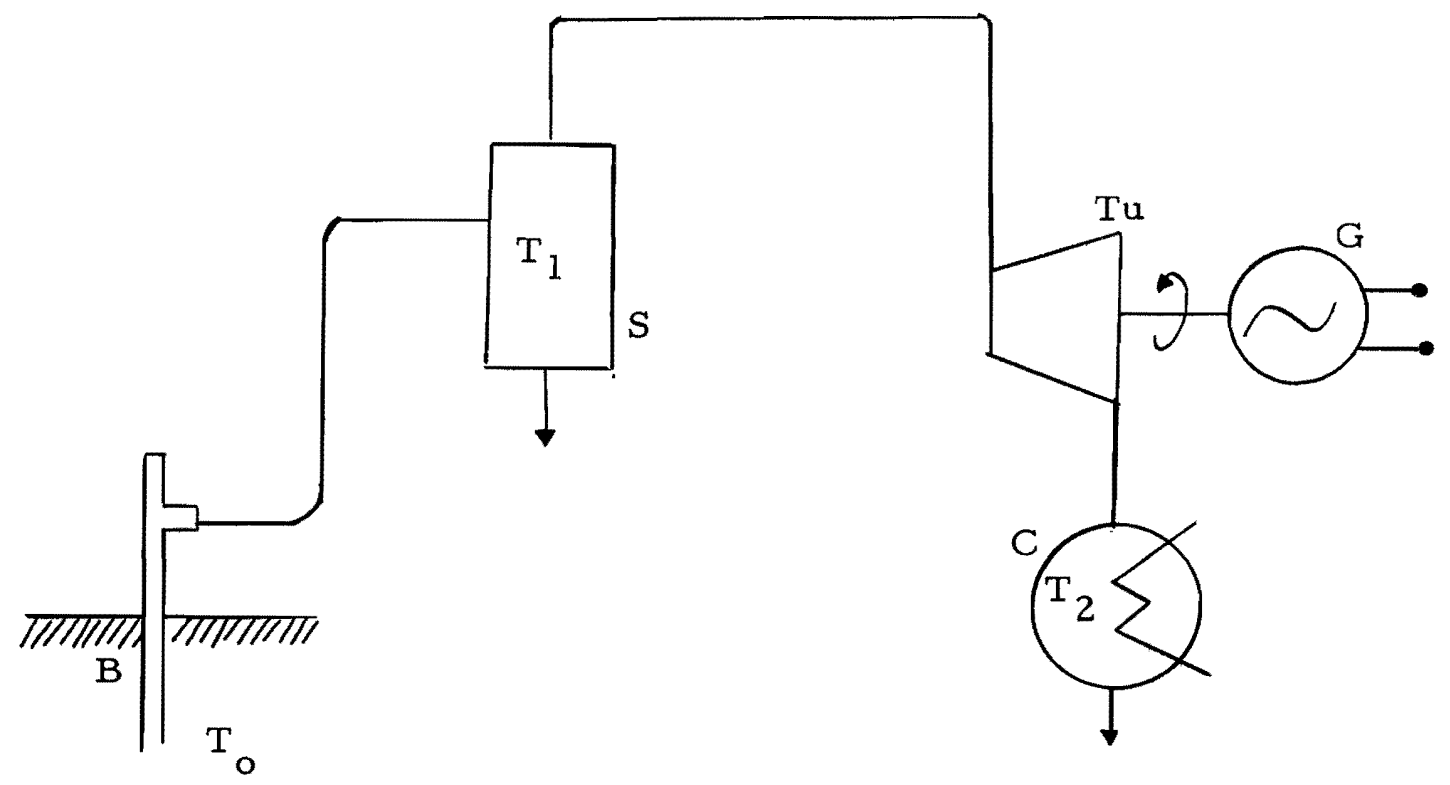

Figure 3. Single flash power cycle (B = borehole, $\bar{C}=$ condenser,$G=$ generator,$S$ - cyclone separator, $\mathrm{Tu}=$ turbine, $\mathrm{T}_{1}=$ flash temperature, ${ }^{\circ} \mathrm{C}$, and $\mathrm{T}_{2}=$ condensate (environment) temperature, ${ }^{\circ} \mathrm{C}$ ). 
diagram for this type of power plant. The system contains: (1) a borehole of a liquid phase reservoir as a natural heat source, (2) a cyclone separator, (3) a steam turbine, (4) an electric power generator and (5) a barometric condenser. A hot geothermal fluid flowing up the borehole is flashed (throttled) to dry steam, which in turn enters the turbine at a temperature (flash temperature) lower than the saturation temperature at reservoir conditions. Through the turbine, it is expanded to a lower pressure and temperature (condensate temperature) at which the exhaust steam is condensed to a saturated liquid. This condensate liquid is in turn used for cooling tower makeup water, or reinjected into the ground. The processes that comprise the cycle are represented on the T-S (temperature-entropy) diagram, shown in Figure 4.

In analyzing this type of power cycle it is helpful to its efficiency as depending on the temperature and pressure at which heat is supplied and the temperature and pressure at which heat is rejected. Any changes that increase the temperature and pressure at which heat is rejected will increase the efficiency of the power cycle. Since we are dealing with a working fluid which is found naturally at a rather low pressure and temperature (and at the same time, these conditions vary 


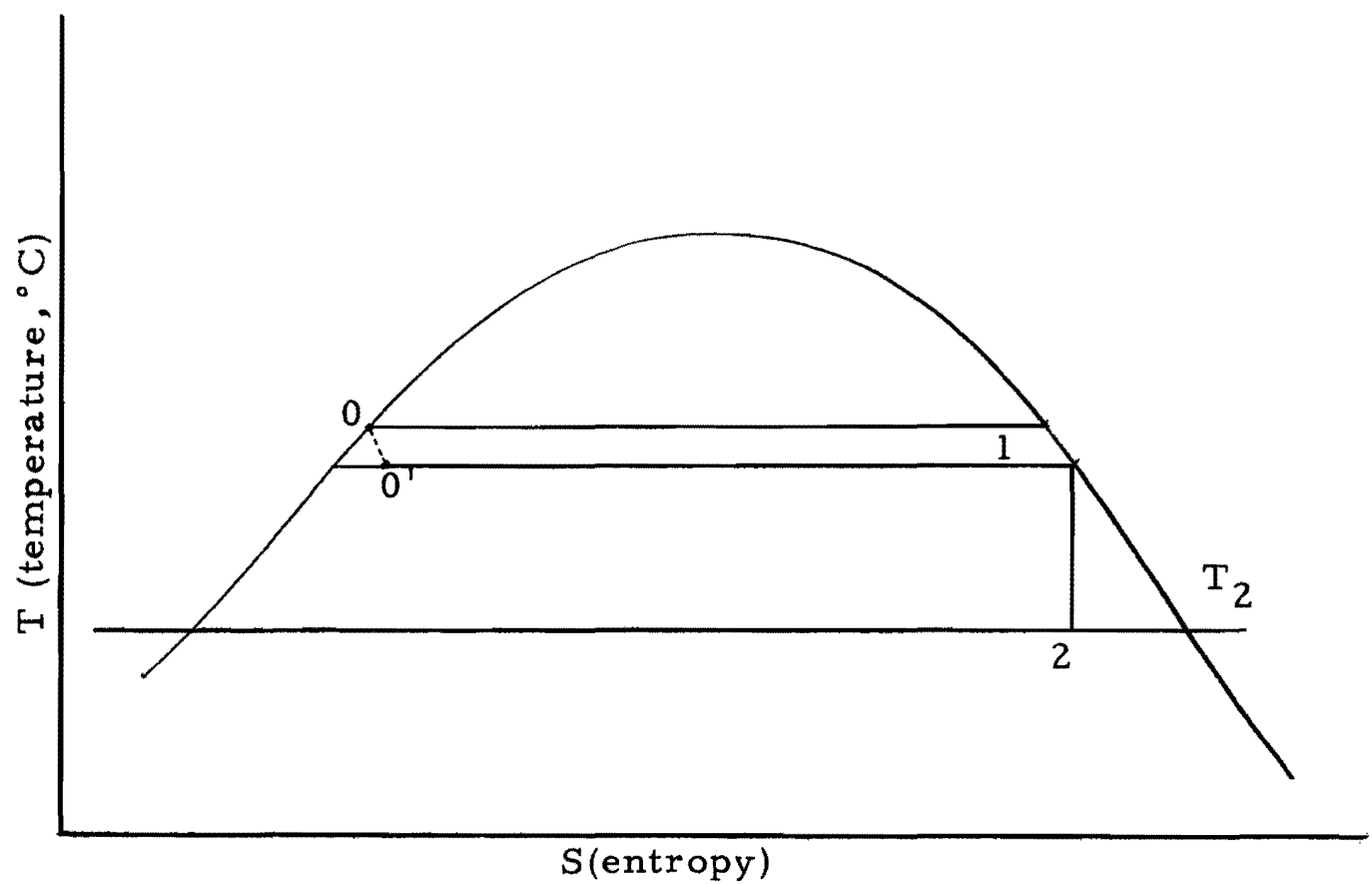

Figure 4. T-S (temperature, entropy) diagram of the single-flash processes. $\left(0-0^{\prime}\right.$ is the throttling process, and $1-2$ is the isentropic process in the turbine). $T_{2}=$ environment temperature (condensate temperature). 
widely from one reservoir to another), the simple flash power cycle has a relatively poor thermal efficiency as compared to the Rankine cycle. Typical geothermal power plant cycle efficiencies are about $14-16 \%$.

The performance calculations for the single-flash power cycle are very simple, and in this case a very much simplified picture is illustrated by the following considerations. Consider a metric ton ( $\mathrm{mt}=1000 \mathrm{~kg}$ ) of geothermal heat carrier (hot water) produced from a liquid-phase reservoir at the saturation temperature $T_{0}$ (reservoir temperature), and having an enthalpy $i_{\circ}$. The water is flashed (throttled) to steam, which in turn expands in a turbine from $T_{1}$ (flash temperature), and is condensed in a barometric condenser at $\mathrm{T}_{2}$ (environment temperature). We will compute the amount of mechanical work or exergy* (capacity of the unit mass of the reservoir fluid to produce mechanical work) which can be derived from the total heat content (enthalpy) of this fluid. The composition of the flash fluid is given by the weight of vapor (dry vapor), X, contained in one kilogram of the mixture. It is referred to as the quality of the mixture and is obtained by the equation

* The concept of exergy is discussed in Appendix IV. 


$$
X=\frac{\Delta i^{\prime}}{r_{1}}
$$

or

$$
x=\frac{i_{0}^{\prime}-i_{1}^{\prime}}{r_{1}}
$$

where:

$$
\begin{aligned}
i_{0}^{\prime}= & \text { the enthalpy }(\mathrm{cal} / \mathrm{kg}) \text { of the geothermal fluid } \\
& \text { at the reservoir temperature, } \mathrm{T}_{0}\left({ }^{\circ} \mathrm{C}\right) \\
\mathrm{i}_{1}^{\prime}= & \text { the enthalpy }(\mathrm{cal} / \mathrm{kg}) \text { of the flash effluent resi- } \\
& \text { dual water at the flash temperature, } \mathrm{T}_{1}\left({ }^{\circ} \mathrm{C}\right) \\
\mathrm{r}_{1}= & \text { the latent heat of evaporation at } \mathrm{T}_{1}(\mathrm{cal} / \mathrm{kg})
\end{aligned}
$$

Another important quantity is the specific consumption, $g$, of steam by the power cycle. By this, we mean the quantity of steam (in $\mathrm{kg}$ ) consumed in the generation of $1 \mathrm{kw}-\mathrm{hr}$ of electrical energy. Since $1 \mathrm{kw}-\mathrm{hr}=860 \mathrm{cal}$, the work or exergy in the single-flash cycle is, theoretically,

$$
E=i_{1}^{\prime \prime}-i^{\prime \prime} 2=\Delta i^{\prime \prime}
$$

where:

$$
\begin{aligned}
& i_{1}{ }^{\prime \prime}=\text { the enthalpy }(\mathrm{cal} / \mathrm{kg}) \text { of the flashed steam at } \\
& \mathrm{T}_{1}\left({ }^{\circ} \mathrm{C}\right) \\
& \mathrm{i}_{2}^{\prime \prime}=\text { the enthalpy of flashed steam at } \mathrm{T}_{2}\left({ }^{\circ} \mathrm{C}\right)
\end{aligned}
$$

so that the theoretical specific consumption of steam is

$$
g=\frac{860}{\Delta i^{\prime \prime}} \mathrm{kg} \text { of } \mathrm{steam} / \mathrm{kw}-\mathrm{hr}
$$


where $\Delta i^{\prime \prime}$ is the isentropic expansion in the turbine. Therefore, the exergy generated by this cycle per unit mass reservoir fluid is determined from equations (3.1) and (3.2), yielding

$$
E=\frac{X}{g}
$$

or

$$
E=\frac{\left(\Delta i^{\prime}\right)\left(\Delta i^{\prime \prime}\right)}{860 r_{1}} \quad \frac{k w-h r}{m t}
$$

The quantity $E$ as defined by equation (3.3) is the theoretical work $(\mathrm{kw}-\mathrm{hr})$ derived from one ton of geothermal fluid taking part in a single-flash power plant. These plants utilize a large enthalpy difference, and their gross steam consumption is of the order of approximately $10 \mathrm{~kg} / \mathrm{kw}-\mathrm{hr},(6)$.

\section{DOUBLE-FLASH POWER CYCLES}

More complex power cycles have been developed to improve upon the efficiency of a given geothermal reservoir. One type of cycle commonly used in modern geothermal power plants is the multi-flash poser cycle. A simple flow diagram of this is shown in Figure 5. These cycles will have a higher installation cost, and they will be limited to liquid phase reservoirs producing high temperature water. Geothermal power plants of this type have been built in New Zealand, using three stages with a separate turbine for each pressure (15). 


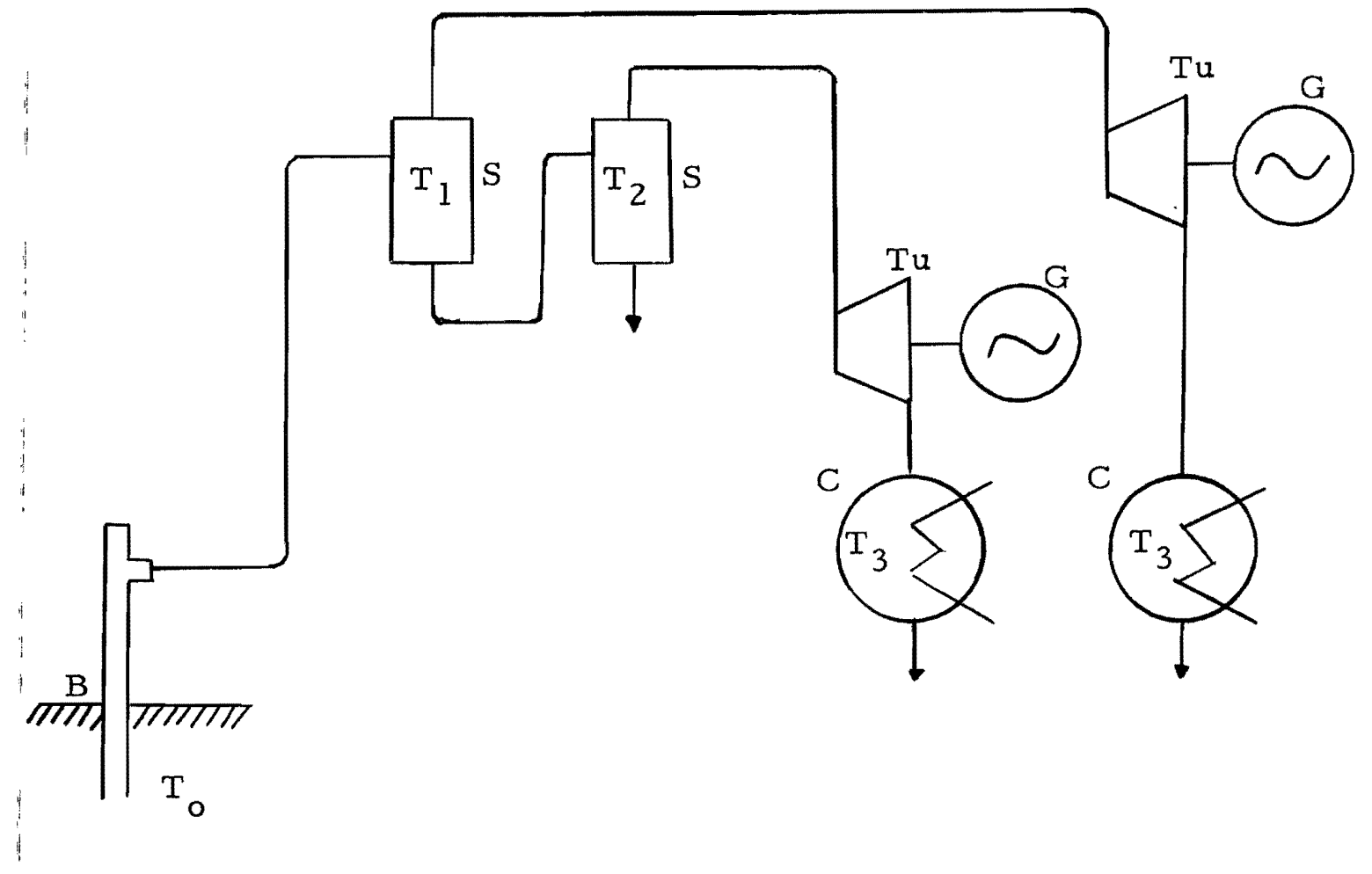

Figure 5. Double flash power cycle. $(B=$ borehole, $\bar{C}=$ condenser, $G$ = generator, $\mathrm{S}=$ cyclone separator (shere flashing occurs), $\mathrm{Tu}=$ turbine, $\mathrm{T}_{\mathrm{o}}=$ reservoir temperature, ${ }^{\circ} \mathrm{C}, \mathrm{T}_{1}=$ flash temperature for the first stage, ${ }^{\circ} \mathrm{C}, \mathrm{T}_{2}=$ flash temperature for the second stage, ${ }^{\circ} \mathrm{C}$, and $\mathrm{T}_{3}=$ condensate (environment) temperature, ${ }^{\circ} \mathrm{C}$. 
Two flash stages are involved in this double-flash power system, where the residual flash water from the first steam separator can be flashed again at lower temperature and more steam can thus be generated. The number of stages chosen for a practical cycle would be a matter of balancing plant economical cost against kilowatt rating. From a practical point of view, some implications outlined by Hansen (15) and Bodvarsson (6) indicate that the use of a two-stage power plant gives a theoretical gain of 24 percent over one stage, and an addition of a third stage of flashing yields an additional 11 percent. Therefore, a diminishing gain would result from each additional stage.

The performance calculations for the double-flash power cycle are a little more complicated than for the singleflash power cycle.A T-S (temperature-entropy) diagram presenting the precesses that comprise the cycle, is shown in Figure 6.

The working fluid composition, the specific consumption of steam, and the mechanical work (exergy) for this cycle is determined as follows:

For the first stage:

$$
x_{1}=\frac{\left(\Delta i^{\prime}\right)_{1}}{r_{1}}
$$




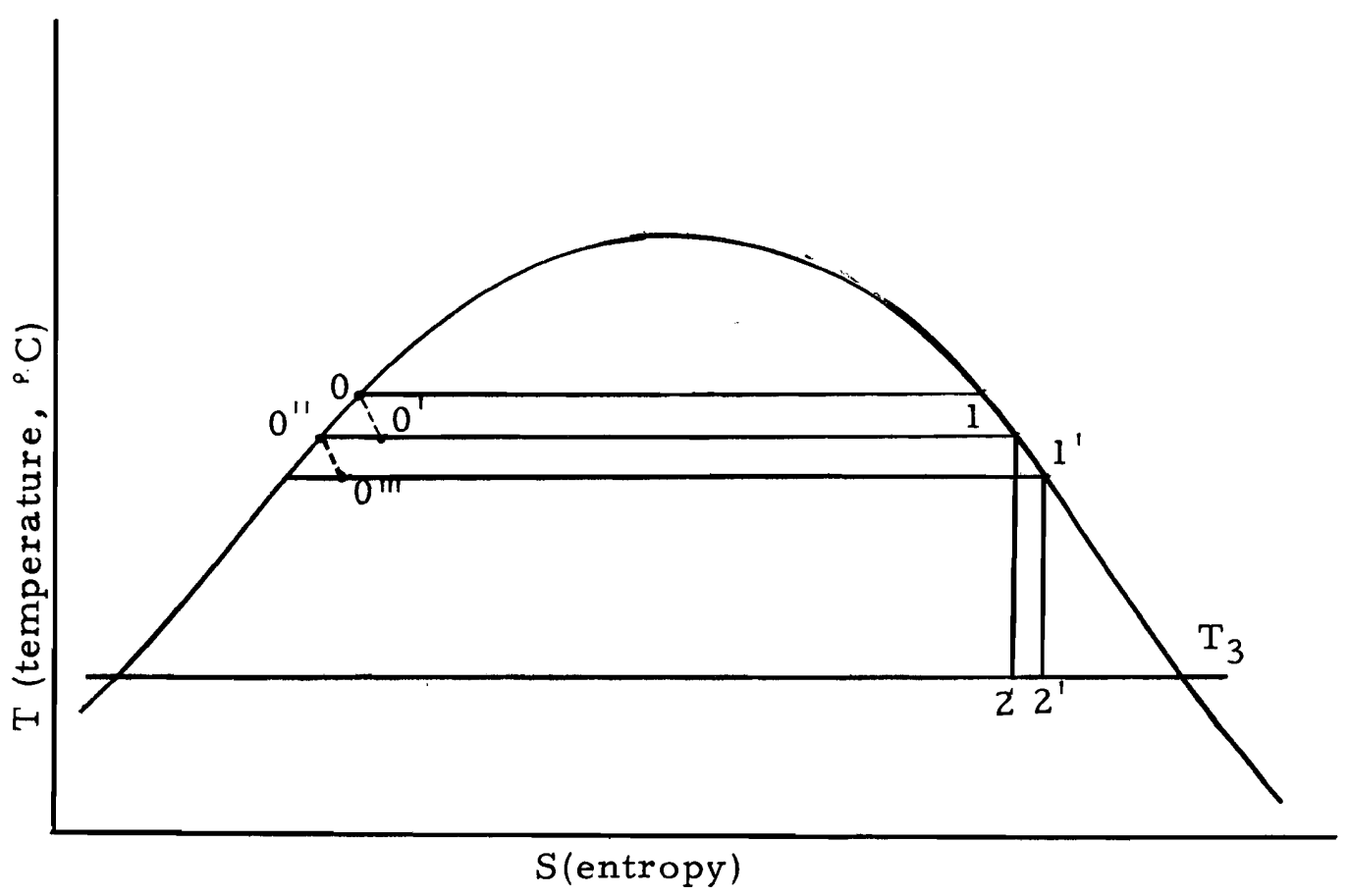

Figure 6. T-S (temperature-entropy) diagram for the double-flash processes. $\left(0-0^{\prime}, 0^{\prime \prime}-0^{\prime \prime \prime}\right.$ are the throttling (flashing) processes at first and second stages). $1-2,1^{\prime}-2^{\prime}$ are the isentropic processes in the turbine. $\mathrm{T}_{3}=$ environment temperature condensate temperature). 
or

$$
x_{1}=\frac{i^{\prime} e^{-i^{\prime}} 1}{r_{1}}
$$

where:

$$
\begin{aligned}
& x_{1}=\text { the dryness factor (quality) of the reservoir } \\
& \text { fluid in the first stage } \\
& i_{0}^{\prime}=\text { the enthalpy (cal/kg) of the geothermal fluid } \\
& \text { at the reservoir temperature } \mathrm{T}_{\mathrm{o}}\left({ }^{\circ} \mathrm{C}\right) \\
& i^{\prime}{ }_{1}=\text { the enthalpy (cal/kg) of the flash effluent } \\
& \text { residual water at the flash temperature } \mathrm{T}_{1}\left({ }^{\circ} \mathrm{C}\right) \\
& \text { in the first stage } \\
& r_{1}=\text { the latent heat of evaporation }(\mathrm{cal} / \mathrm{kg}) \text { in the } \\
& \text { first stage }
\end{aligned}
$$

The specific consumption of steam in the first stage

is

$$
g_{1}=\frac{860}{\left(\Delta i^{\prime \prime}\right)_{1}} \quad \frac{\mathrm{kg} \text { of steam }}{\mathrm{kw}-\mathrm{hr}}
$$

where $\left(\Delta i^{\prime \prime}\right)_{1}$ is the isentropic expansion in the turbine of the first stage. The exergy (per unit mass of reservoir fluid) is

$$
E_{1}=\frac{X_{1}}{g_{1}}
$$

or

$$
E_{1}=\frac{\left(\Delta i^{\prime}\right)_{1}\left(\Delta i^{\prime \prime}\right)_{1}}{860 r_{1}} \quad \frac{k w-h r}{m t}
$$


For the second stage the dryness fraction of the mixture from the second separator, which separates vapor from the residual liquid from the first separator, is

$$
x_{2}=\frac{\left(\Delta i^{\prime}\right)_{2}}{r_{2}}=\frac{i^{\prime}{ }^{-} i^{\prime} 2}{r_{2}}
$$

where:

$i_{1}^{\prime}=$ the enthalpy (cal/kg) of the residual water at temperature $\mathrm{T}_{1}\left({ }^{\circ} \mathrm{C}\right)$ in the first stage

$\mathbf{i}_{2}^{\prime}=$ the enthalpy (cal/kg) of the residual water at temperature $\mathrm{T}_{2}\left({ }^{\circ} \mathrm{C}\right)$ in the second $\mathrm{stage}$

$r_{2}=$ the latent heat of evaporation (cal $/ \mathrm{kg}$ ) at $T_{2}$

The specific consumption of steam in the second stage is determined by the equation

$$
g_{2}=\frac{860}{\left(\Delta i^{\prime \prime}\right)_{2}}
$$

or

$$
g_{2}=\frac{860}{i^{\pi} 2^{-i^{11}}}\left(\frac{k g \text { of steam }}{k w-h r}\right)
$$

where:

$i_{2}^{\prime \prime}=$ the enthalpy of flash steam at $T_{2}$ (flash temperature of the second stage, ${ }^{\circ} \mathrm{C}$

$i_{3}^{\prime \prime}=$ the enthalpy of flash steam at $T_{3}$ (condensate environment tempe rature), ${ }^{\circ} \mathrm{C}$ 
where $\left(\Delta i^{\prime \prime}\right)_{2}$ is the isotropic expansion in the turbine of the second stage.

The exergy (per unit mass reservoir fluid) by the second stage is

$$
E_{2}=\left(1-x_{1}\right) \frac{x_{2}}{g_{2}}
$$

and therefore, the total exergy (per unit mass reservoir fluid) generated by the double-flash power cycle is the sum of the exergy in the first stage and the exergy generated in the second stage, or,

$$
E_{\text {total }}=E_{1}+E_{2}
$$

or

$$
E_{\text {total }}=\left[\frac{x_{1}}{g_{1}}+\left(1-x_{1}\right) \frac{x_{2}}{g_{2}}\right]=\left(\frac{k w-h r}{m t}\right)
$$

These thermodynamic relationships will be utilized in the next chapter for the development of the optimum operation temperatures (flash temperatures) for which the cycle power output is a maximum. 


\section{CHAPTER IV}

\section{THERMODYNAMIC OPTIMIZATION OF SINGLE- AND DOUBLE-FLASH POWER CYCLES}

In the preceding analysis for geothermal power cycles (single and multiflash processes), the general procedure has been to establish a thermodynamic relationship that will provide the maximum amount of power obtainable from a geothermal power plant. According to Bodvarsson (6), the borehole mass flow in a liquid phase reservoir decreases with increasing operating pressure and temperature, whereas the power cycle output increases with increasing turbine inlet pressure and temperature and decreasing outlet pressure and temperature. The determination of the optimum operating temperature at both ends of the turbine is therefore a typical problem of optimization. This chapter discusses and illustrates two methods of optimization which have been utilized to determine these optimum operation conditions: the graphical method and analytical method. In the graphical method values of $E$ (exergy) are plotted against values of $T_{1}$ (flash temperature) and the optimum flash temperature $\mathrm{T}_{1}$ is obtained where $E$ is a maximum. On the other hand, the analytical method on the basis of first and second order approximations 
(first and second degree polynomial approximations) where the optimum value $T_{1}$ (steam flash temperatures) in the case of single-flash power cycle, and values of $\left(T_{1}\right)_{1}$ of first stage, $\left(\mathrm{T}_{2}\right)_{2}$ of second stage for the double-flash power cycle are found at the optimum point where $\partial \mathrm{E} / \partial \mathrm{T}_{1}$ and $\left(\partial \mathrm{E} / \partial \mathrm{T}_{1}\right)_{1}$ and $\left(\partial \mathrm{E} / \partial \mathrm{T}_{2}\right)_{2}$ respectively are equal to zero.

For the case of the single-flash power cycle, the optimum value of $T_{1}$ (flash temperature) where the value of $E$ (exergy) is maximum is obtained graphically. This method has been utilized on the basis of i-s (enthalpy-entropy) diagram, and it is less convenient for double-flash processes.

In the analytical method, the first and second order approximations are used for single flash processes. For the double-flash processes only the first order approximation procedure (first order Taylor series approximations) has been utilized with the help of the first order iteration method.

\section{GRAPHICAL METHOD: SINGLE-FLASH PROCESSES}

This method of optimization is based on the assumption that a hot geothermal fluid is flowing up boreholes from a liquid phase reservoir at a fixed flow rate. The amount of exergy which can be obtained per unit mass of geothermal fluid depends on the following relationships: 
1. The lower the flash temperature and pressure, the greater will be the amount of flash steam produced for power generation.

2. As the steam pressure is reduced, the exergy of the steam is reduced.

3. As the flash temperature is reduced, the increas ing steam flow and diminishing exergy result in increasing power cycle output until an optimum temperature is reached.

At temperatures below this optimum the reduced exergy per unit mass of flow more than offsets any further gain due to increased flow. Under these conditions, the optimum temperature is found at the maximum point of the curve obtained by plotting the exergy per unit mass of geothermal fluid flow versus flash temperatures. Figures 7,8 and 9 present these curves for the cases of geothermal fluid at temperatures $T_{0}$ of $180^{\circ} \mathrm{C}$, $260^{\circ} \mathrm{C}$ and $300^{\circ} \mathrm{C}$. The optimum flash temperatures in these cases are shown in Table.IV for the cases when the turbine exhaust temperatures are $30^{\circ} \mathrm{C}, 40^{\circ} \mathrm{C}$ and $50^{\circ} \mathrm{C}$. These results were obtained by using equations $(3.1),(3.2)$ and (3.3), and the data was generated from the i-s diagram and steam tables (29) 


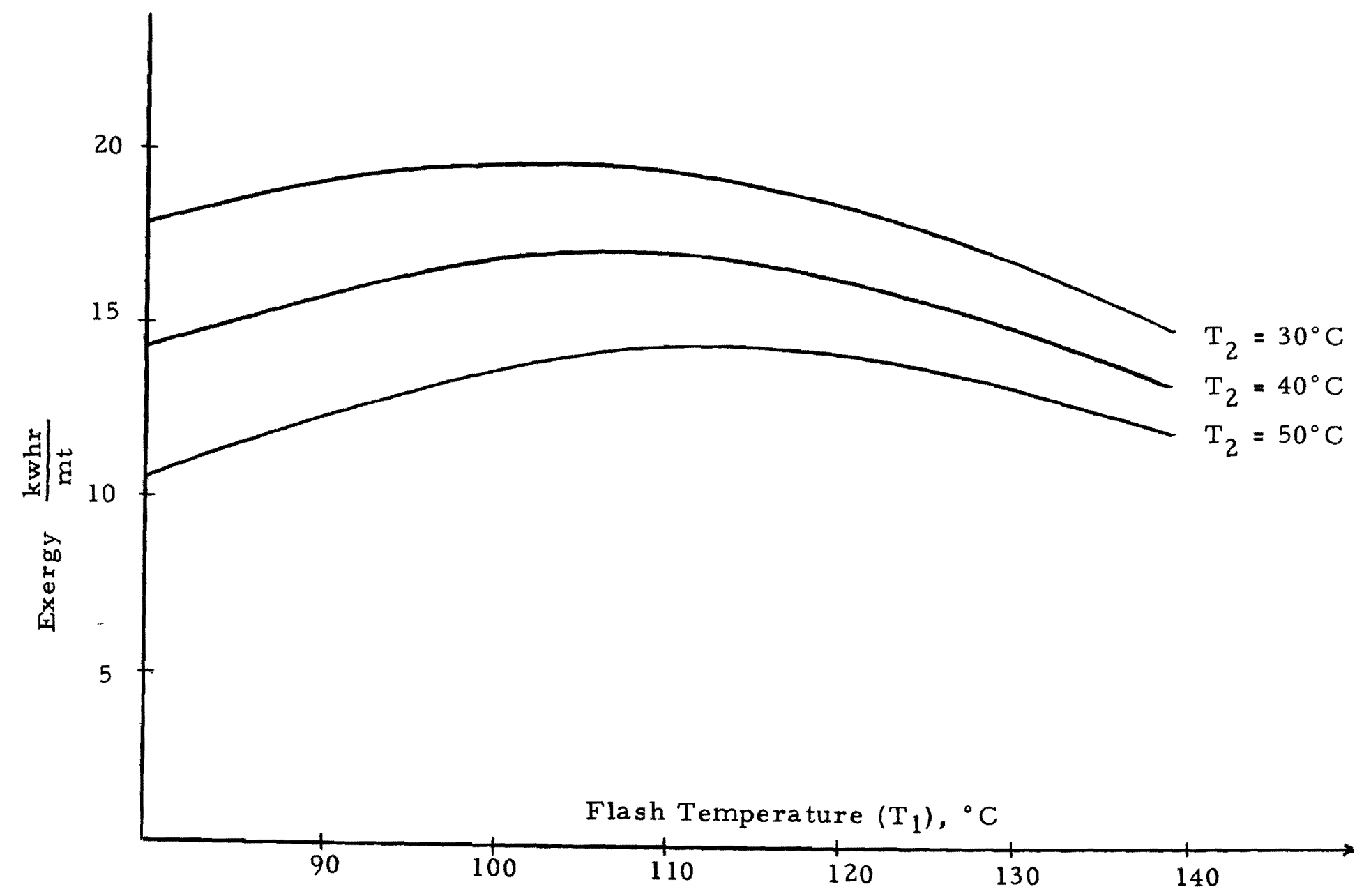

Figure 7. Determination of Optimum Flash Temperature for the Case $\mathrm{T}_{\mathrm{o}}=180^{\circ} \mathrm{C}$ : Graphical Method. 


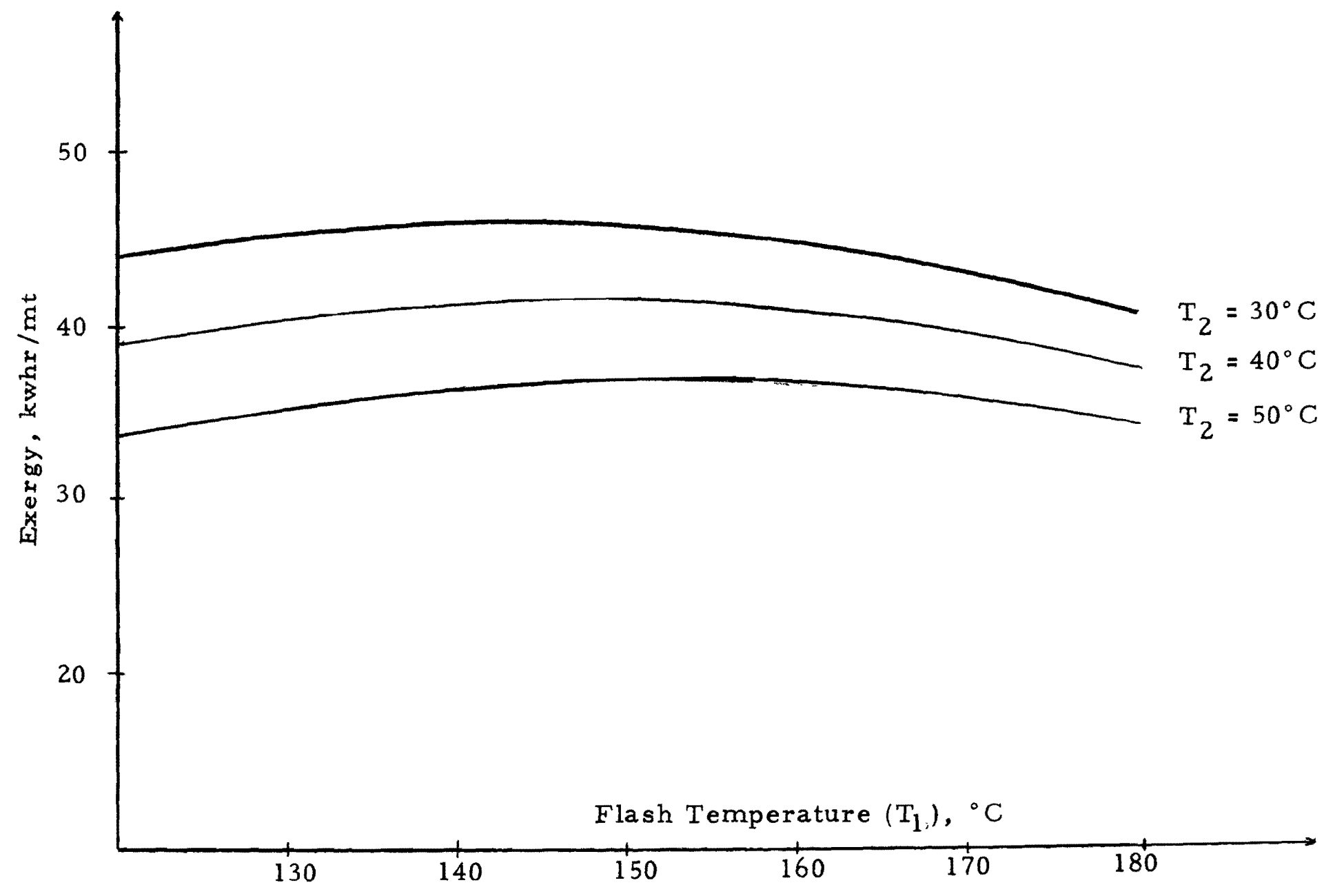

Figure 8. Determination of Optimum Flash Temperature for the Case $\frac{T_{i}}{T_{i}} 260^{\circ} \mathrm{C}:$ Graphical Method. 


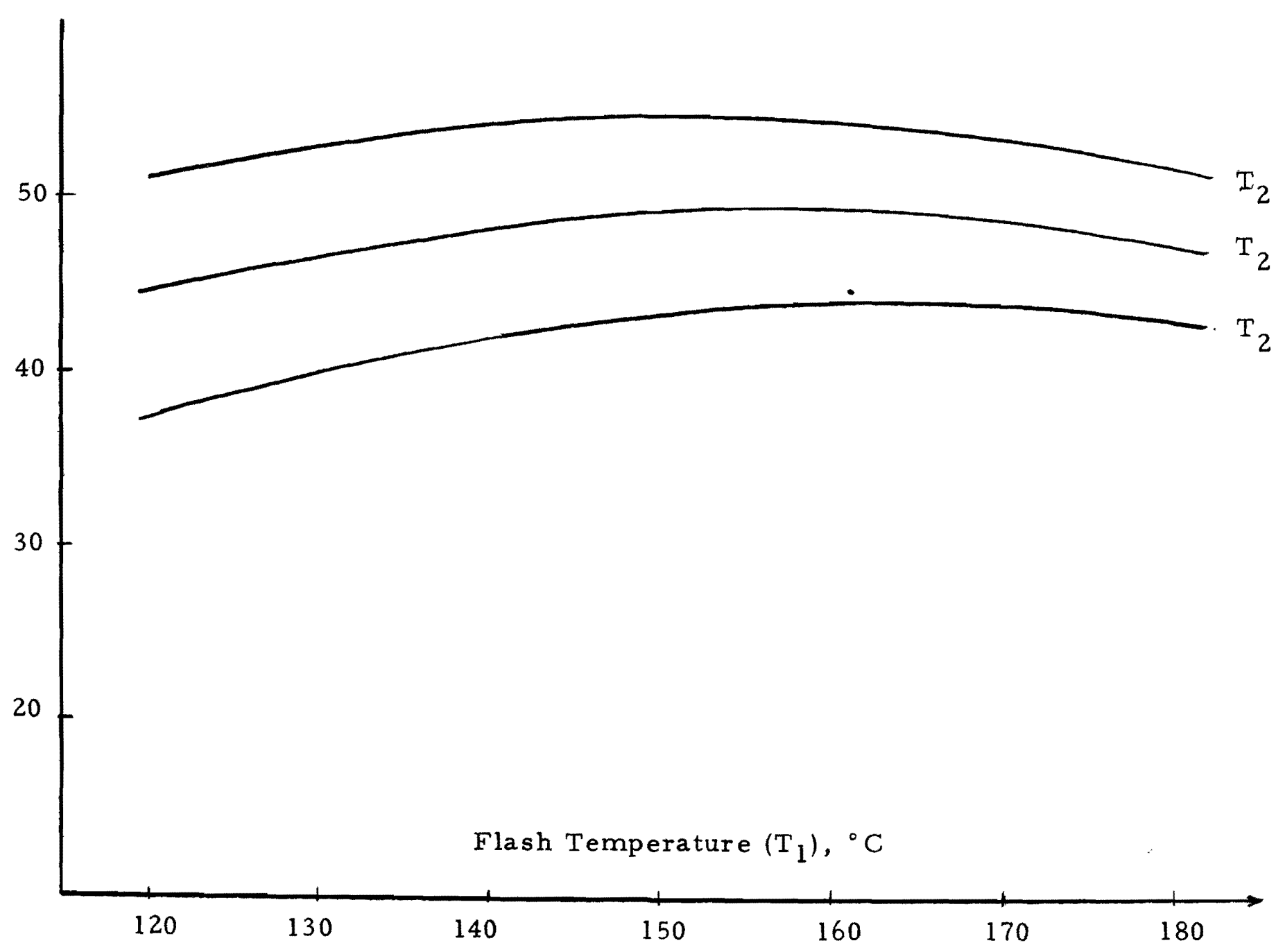

Figure 9. Determination of Optimum Flash Temperatures for the Case $\mathrm{T}_{\mathrm{o}}=300^{\circ} \mathrm{C}$ : Graphical Method. 
TABLE IV

PERFORMANCE OF SINGLE-FLASH CYCLE

GRAPHICAL METHOD

\begin{tabular}{cccc}
$\begin{array}{c}\text { Reservoir } \\
\text { temperature } \\
\mathrm{T}_{\mathrm{o}}\left({ }^{\circ} \mathrm{C}\right)\end{array}$ & $\begin{array}{c}\text { Environment } \\
\text { temperature } \\
\mathrm{T}_{2}\left({ }^{\circ} \mathrm{C}\right)\end{array}$ & $\begin{array}{c}\text { Optimum flash } \\
\text { temperature } \\
\mathrm{T}_{1}\left({ }^{\circ} \mathrm{C}\right)\end{array}$ & $\begin{array}{c}\text { Maximum } \\
\text { exergy, } \\
(\mathrm{kw}-\mathrm{hr} / \mathrm{mt})\end{array}$ \\
\hline $\begin{array}{l}30 \\
40\end{array}$ & 105 & 19.5 \\
& 50 & 110 & 17.0 \\
260 & 30 & 115 & 14.2 \\
& 40 & 145 & 46.0 \\
300 & 50 & 150 & 41.5 \\
& 30 & 165 & 38.5 \\
& 40 & 170 & 65.0 \\
& 50 & 175 & 59.6
\end{tabular}




\section{ANALYTICAL METHOD: FIRST ORDER APPROXIMATION FOR SINGLE- FLASH PROCESSES}

The theoretical optimum flash temperature obtained by the graphical method in the previous section can also be determined analytically by making use of the classical technique of differential calculus, for which the optimum value of $T_{1}$ (flash steam temperature into the turbine) is found at the point where $\left(\partial E / T_{1}\right)$ is equal to zero. Again, if we assume a fixed rate of flow from a liquid phase reservoir at $T_{0}$, having an enthalpy $i_{0}^{\prime}$ and the fluid is flashed to steam at $T_{1}$, and expands in a turbine from an initial temperature $T_{1}$ to a final temperature $T_{2}$ (condensate temperature), the work performed by the power cycle will be a maximum at an optimum operating condition. To the first linear approximation, by taking into account that the change in enthalpy is not a linear function of temperature differ ence, the following equations show the effect of the variables $T_{1}$ and $T_{2}$ on the exergy for this case

$$
E=\frac{\left(\Delta i^{\prime}\right)\left(\Delta i^{\prime \prime}\right)}{860 r_{1}}
$$

where we have assumed the following simple linear relations

$$
\Delta i^{\prime}=a\left(T_{0}-T_{1}\right)
$$


and

$$
\Delta i^{\prime \prime}=b\left(T_{1}-T_{2}\right)
$$

Therefore, by substitution we get by using metric units

$$
E=\frac{a b}{860 r_{1}}\left(T_{0}-T_{1}\right)\left(T_{1}-T_{2}\right)
$$

where $a$ and $b$ are assumed to be constants and are referred to as parameters of the first order linear function. For this case of linear estimation, the latent heat of evaporation $r_{1}$ is assumed to be constant. Since the quantity $E$ as shown in equation (4.1) has to be a maximum, the optimum value can be found analytically by setting the derivative of $E$ with respect of $T_{1}$ equal to zero and solving for $T_{1}$.

$$
\begin{aligned}
& \frac{d E}{d T_{1}}=T_{0}+T_{2}-2 T_{1}=0, \\
& \left(T_{1}\right)_{\text {optimum }}=\frac{1}{2}\left(T_{0}+T_{2}\right)
\end{aligned}
$$

The quantity $T_{1}$ given by equation (4.2) is the theoretical optimum flash temperature, which is the average of the reservoir temperature and the condensate temperature. For an example, a geothermal power plant which is operated on the basis of geothermal water at a temperature of $\mathrm{T}_{0}=260^{\circ} \mathrm{C}$ and $T_{2}=50^{\circ} \mathrm{C}$, the theoretical optimum flash temperature $T_{1}=155^{\circ} \mathrm{C}$. This result indicates almost an exact similarity with the optimum conditions obtained by the graphical method. 
III. ANALYTICAL METHOD: SECOND ORDER APPROXIMATION FOR SINGLE-FLASH

PROCESSES

The investigation of optimality in this section is an example of a general algebraic technique involving second order approximation. The same thermodynamic principles used in the previous section for the first order approximation can be applied for this case. The purpose of this special technique is to obtain a greater accuracy in locating the best operating flash temperature for which the exergy per unit mass of a geothermal fluid is a maximum.

Following the same argument as before, instead of

$$
\Delta i^{\prime}=a\left(T_{0}-T_{1}\right)
$$

and

$$
\Delta \mathrm{i}^{\prime \prime}=\mathrm{b}\left(\mathrm{T}_{1}-\mathrm{T}_{2}\right),
$$

we assume now the following more accurate relations

$$
\Delta i^{\prime}=a\left(T_{0}-T_{1}\right)+b\left(T_{0}^{2}-T_{1}^{2}\right)
$$

or

$$
\Delta i^{\prime}=a\left(T_{0}-T_{1}\right)\left(1+\frac{b}{a}\left(T_{0}+T_{1}\right)\right.
$$

where $a$ and $b$ are constants. Also, for the adiabatic process in the turbine, we assume

$$
\Delta i^{\prime \prime}=K\left(T_{1}-T_{2}\right)+S\left(T_{1}^{2}-T_{2}^{2}\right)
$$


or

$$
\Delta \mathrm{i}^{\prime \prime}=\mathrm{K}\left(\mathrm{T}_{1}-\mathrm{T}_{2}\right)\left(1+\frac{\mathrm{S}}{\mathrm{K}}\left(\mathrm{T}_{1}+\mathrm{T}_{2}\right)\right)
$$

where $\mathrm{K}$ and $\mathrm{S}$ are constants. The second order terms $\mathrm{b}\left(\mathrm{T}_{\mathrm{o}}{ }^{2}-\mathrm{T}_{1}^{2}\right)$, and $\mathrm{S}\left(\mathrm{T}_{1}^{2}-\mathrm{T}_{2}^{2}\right)$ in equations (4.3) and (4.4) and referred to as correction factors. By adding the second order terms, we take into account that the change in enthalpy actually is not a linear function of the temperature difference. The constants $a, b, K$ and $S$ may be referred to as algebraic parameters. We next consider the case of the latent heat of evaporation $r$, and assume the following relation

$$
r\left(T_{1}\right)=r_{0}\left(1+\beta T_{1}\right)
$$

where:

$$
\begin{aligned}
& T_{1}=\text { the flash temperature, }{ }^{\circ} \mathrm{C} \\
& \beta=\text { a constant } \\
& r_{0}=a \text { constant }
\end{aligned}
$$

If the flash steam enters the turbine at $T_{1}$ and leaves at $T_{2}$, the exergy per unit mass of flow is given by (using metric units)

$$
E=\frac{\left(\Delta i^{\prime}\right)\left(\Delta i^{\prime \prime}\right)}{860 r}
$$


Then, by substituting the values for $\Delta i^{\prime}, \Delta i^{\prime \prime}$, and $r$ given by equations $(4.3),(4.4)$ and $(4.5)$, the exergy equation becomes $E=\frac{k a}{860 r_{o}}\left(\left(T_{o}-T_{1}\right)\left(T_{1}-T_{2}\right)\right)\left(1+\frac{b}{a}\left(T_{0}+T_{1}\right)\right)\left(1+\frac{S}{K}\left(T_{1}+T_{2}\right)\left(1-\beta T_{1}\right)\right.$

For a matter of simplification, let us denote

$$
a=\frac{b}{a}
$$

and

$$
\gamma=\frac{S}{K}
$$

so that equation $(4.6)$ becomes

$E=\frac{k a}{860 r_{o}}\left(\left(T_{o}-T_{1}\right)\left(T_{1}-T_{2}\right)\right)\left(1+a\left(T_{0}+T_{1}\right)\right)\left(1+\gamma\left(T_{1}+T_{2}\right)\right)\left(1-\beta T_{1}\right)$

Because the constant a turns out to be very small compared to the other two constants $\gamma$ and $\beta$ (see Appendices), therefore, we neglect $a$ by putting $a=0$. Then neglecting the product $\gamma \beta$, equation (4.7) takes the for $m$

$$
E=\frac{k a}{860 r_{o}}\left(\left(T_{\circ}-T_{1}\right)\left(T_{1}-T_{2}\right)\left(1+\gamma T_{2}+(\gamma-\beta) T_{1}\right)\right.
$$


The optimum operational value of $T_{1}$ can be found analytically by maximizing $\mathrm{E}$ by setting the derivative of $\mathrm{E}$ with respect to $\mathrm{T}_{1}$ equil to zero and solve for $T_{1}$

$$
\begin{aligned}
\frac{d E}{d T_{1}}= & \left(T_{0}-2 T_{1}+T_{2}+2(\gamma-\beta) T_{0} T_{1}-(\gamma-\beta) T_{0} T_{2}-3(\gamma-\beta) T_{1}{ }^{2}+\right. \\
& \left.+2(\gamma-\beta) T_{1} T_{2}+\gamma T_{0} T_{2}-2 \gamma T_{2} T_{1}+\gamma T_{2}{ }^{2}\right)
\end{aligned}
$$

At the optimum point,

$$
\begin{aligned}
& T_{0}-2 T_{1}+T_{2}+2(\gamma-\beta) T_{0} T_{1}-(\gamma-\beta) T_{0} T_{2}-3(\gamma-\beta) T_{1}^{2}+2(\gamma-\beta) T_{1} T_{2}+ \\
& +\gamma T_{0} T_{2}-2 \gamma T_{2} T_{1}+\gamma T_{2}^{2}=0 .
\end{aligned}
$$

Let us denote all the correction terms in equation ( 4.9 ) by the letter $\mu$, such as

$$
\begin{aligned}
\mu= & 2(\gamma-\beta) T_{0} T_{1}-(\gamma-\beta) T_{0} T_{2}-3(\gamma-\beta) T_{1}{ }^{2}+2(\gamma-\beta) T_{1} T_{2}+ \\
& +\gamma T_{0} T_{2}-2 \gamma T_{2} T_{1}+\gamma T_{2}{ }^{2} .
\end{aligned}
$$

Substituting the value $\frac{T_{0}+T_{2}}{2}$ (obtained by the first order approximation technique) for $T_{1}$ in the second order terms in equatior $(4.10)$, we obtain

$$
\mu=\frac{(\gamma-\beta)\left(T_{0}^{2}-2 T_{0} T_{2}+T_{2}^{2}\right)}{4}
$$

or

$$
\mu=\frac{(\gamma-\beta)}{4}\left(T_{0}-T_{2}\right)^{2}
$$


Then, substitute equation (4.11) back in equation (4.9), we get

$$
\mathrm{T}_{0}=2 \mathrm{~T}_{1}+\mathrm{T}_{2}+\frac{(\gamma-\beta)}{4}\left(\mathrm{~T}_{\mathrm{o}}-\mathrm{T}_{2}\right)^{2}=0
$$

solving for $\mathrm{T}_{1}$, therefore,

$$
\left(\mathrm{T}_{1}\right)_{\text {opt. }}=\frac{1}{2}\left(\mathrm{~T}_{\mathrm{o}}+\mathrm{T}_{2}\right)+\frac{(\gamma-\beta)}{8}\left(\mathrm{~T}_{\mathrm{o}}-\mathrm{T}_{2}\right)^{2}
$$

where $\frac{(\gamma-\beta)}{8}\left(T_{0}-T_{2}\right)^{2}$ is the second order correction factor. The optimum temperature defined by equation $(4.12)$ is a more exact optimum at which the exergy per unit mass of a geothermal fluid is approximately a maximum.

IV. NUMERICAL CALCULATIONS LEADING TO THE OPTIMUM FLASH TEMPERATURE FOR SINGLE-FLASH POWER CYCLE

With the help of the first order iterated linear interpolation method numerical calculations have been carried out to determine the flash temperature optima of the single-flash power cycle. From the i-s diagram and tables of saturated steam (by temperatures) (29) we obtained the data required for such calculations. The following is a summary of the procedure used in order to carry the numerical calculations for a number of cases:

1. Derive the constants $a, b$, on the basis of the steam tables, and then obtain the constant denoted by a from the following equation, 
including the second order terms (second

degree polynomial)

$\Delta i^{\prime}=a\left(T_{0}-T_{1}\right)+b\left(T_{0}^{2}-T_{1}^{2}\right)$

divide both sides of the equation by $\left(T_{0}-T_{1}\right)$, then

$$
\frac{\Delta i^{\prime}}{T_{0}-T_{1}}=a+b\left(T_{o}+T_{1}\right)
$$

Where $T_{1}=\frac{T_{0}+T_{2}}{2}$, and it is defined as the

first order optimum temperature (theoretically).

From the equation of the straight line through

the two points $\left(f\left(T_{0}+T_{1}^{*}\right),\left(T_{0}+T_{1}^{*}\right)\right)$ and

$\left(\mathrm{f}\left(\mathrm{T}_{\mathrm{o}}+\mathrm{T}_{1}^{* * *}\right),\left(\mathrm{T}_{\mathrm{o}}+\mathrm{T}_{1}^{* * *}\right)\right)$ of equal intervals, the

constants $b$ and $a$ are

$$
\mathrm{b}=\frac{\frac{\left(\Delta i^{\prime}\right)}{\left(\mathrm{T}_{1}-\mathrm{T}_{1}^{* *}\right)}-\frac{\left(\Delta i^{\prime}\right)}{T_{0}-T_{1}^{*}}}{T_{1}^{* * *}-T_{1}^{* k}}
$$

and

$$
\begin{gathered}
a=\frac{\left(\Delta i^{\prime}\right)}{T_{0}-T_{1}^{*}}-b\left(T_{0}+T_{1}^{* *}\right) \\
\text { where } T_{1}^{* k}<T_{1}<T_{1}^{* *} . \text { Then, } \\
a=\frac{b}{a} .
\end{gathered}
$$


2. Derive the constants $K$, and $S$, then obtain

$$
\begin{aligned}
\gamma & =\frac{S}{K} \text { from } \\
\Delta i^{\prime \prime} & =K\left(T_{1}-T_{2}\right)+S\left(T_{1}{ }^{2}-T_{2}{ }^{2}\right)
\end{aligned}
$$

divide both sides of the equation by $\left(\mathrm{T}_{1}-\mathrm{T}_{2}\right)$,

then

$\frac{\left(\Delta i^{\prime \prime}\right)}{T_{1}-T_{2}}=K+S\left(T_{1}+T_{2}\right)$

where $T_{1}=\frac{T_{0}+T_{2}}{2}$, and $T_{2}=$ constant. From

the equation of the straight line through the two

points $\left(\mathrm{f}\left(\mathrm{T}_{1}{ }^{*}+\mathrm{T}_{2}\right),\left(\mathrm{T}_{1}{ }^{*}+\mathrm{T}_{2}\right)\right)$ and $\left(\mathrm{f}\left(\mathrm{T}_{1}{ }^{* * *}+\mathrm{T}_{2}\right)\right.$,

$\left.\left(T_{1}^{*}+T_{2}\right)\right)$ of equal intervals, the constants $K$

and $S$ are:

$S=\frac{\frac{\left(\Delta i^{\prime \prime}\right)}{T_{1}^{* * *}-T_{2}}-\frac{\left(\Delta i^{\prime \prime}\right)}{T_{1}^{*}-T_{2}}}{T_{1}^{* * *}-T_{1}^{*}}$

and

$\mathrm{K}=\frac{\left(\Delta i^{\prime \prime}\right)}{\mathrm{T}_{1}{ }^{*}-\mathrm{T}_{2}}-\mathrm{S}\left(\mathrm{T}_{1}{ }^{*}+\mathrm{T}_{2}\right)$

where $\mathrm{T}_{1}^{*}<\mathrm{T}_{1}<\mathrm{T}_{1}^{* * *}$. Then,

$\gamma=\frac{S}{K}$

3. Derive the constants $\beta$ by linear interpolation from 


$$
\beta=\frac{\Sigma}{1+\Sigma T_{1}}
$$

and

$$
\Sigma=\frac{\Delta r}{(\Delta \mathrm{T}) \mathbf{r}_{\mathrm{O}}}
$$

where $T_{1}=\frac{T_{0}+T_{2}}{2}, \Delta T=T^{* * *}-T_{1}^{*}$, and $\Delta \mathrm{r}=\mathrm{r}_{1} * *-\mathrm{r}_{1} *$

4. Obtain the correction factor $\mu$, from the formula defined in the equation (4.11)

$$
\mu=\frac{\gamma \beta}{8}\left(T_{0}-T_{2}\right)^{2}
$$

5. Obtain the exact optimum flash temperature from the following formula given by equation (4.12),

$$
\left(T_{1}\right)_{o p t .}=\frac{1}{2}\left(T_{o}+T_{2}\right)+\frac{1}{8}(\gamma+\beta)\left(T_{o}-T_{2}\right)^{2}
$$

6. Return to step 1 and repeat for another case, otherwise stop.

This procedure has been programmed and the experimental program and numerical examples for 31 practical cases and their results are given in Appendix I.

In the determination of the temperature optima for a single-flash power cycle using these two methods, almost the same final results are obtained with very little disagreement. For example, in the case of a geothermal power plant operating 
on the basis of thermal water at temperature $\mathrm{T}_{\mathrm{O}}=260^{\circ} \mathrm{C}$, the optimum flash temperature in this case by the analytical method of second order approximation technique is about $153^{\circ} \mathrm{C}$ with a correction factor ( $\mu$ ) given by equation $(4.11)$ of about $1.9^{\circ} \mathrm{C}$, while the result obtained for this case by the graphical method gives a value of $155^{\circ} \mathrm{C}$.

\section{ANALYTICAL METHOD: FIRST ORDER APPROXIMATION FOR DOUBLE-FLASH PROCESSES}

The unifying theme in the remainder of this chapter is the use of the first approximation to obtain the optimum operation flash temperatures in the first and second stages of a double-flash power cycle as shown in Figure 5. The procedure for determining the optimum operational conditions for this problem may become rather tedious since we are dealing with two variables, the flash temperature $T_{1}$ in the first stage, and the flash temperature $T_{2}$ in the second stage. However, the general approach is the same as when only one variable is involved, The total exergy per unit mass of the reservoir fluid is a function of two variables $T_{1}$ and $T_{2}$, i.e.,

$$
E_{T}=f\left(T_{1}, T_{2}\right)
$$

where the subscript $\mathrm{T}$ refers to the term "total". The relationship represented in equation $(4.13)$ corresponds to the exergy performed by the two stages, hence 


$$
E_{T}=\left(\left(\frac{x_{1}}{g_{1}}\right)+\left(1-x_{1}\right)\left(\frac{X_{2}}{g_{2}}\right)\right)
$$

$x_{1}=$ the dryness fraction in the first stage

$\frac{x_{1}}{g_{1}}=$ the exergy performed by the first stage

$\left(1-x_{1}\right)\left(\frac{x_{2}}{g_{2}}\right)=$ the exergy performed by the second stage

$x_{2}=$ the dryness fraction in the second stage

For the first stage:

$$
\frac{X_{1}}{g_{1}}=\frac{\left(\Delta i^{\prime}\right)_{1}\left(\Delta i^{\prime \prime}\right)_{1}}{860 r_{1}}
$$

or

$$
\frac{X_{1}}{g_{1}}=\frac{C_{0} K_{0}\left(T_{0}-T_{1}\right)\left(T_{1}-T_{3}\right)}{860 r_{1}}
$$

where:

$$
\begin{aligned}
& \mathrm{C}_{0} \mathrm{~K}_{0}=\text { constants or parameters } \\
& \mathrm{T}_{3}=\text { the condensate temperature, and it is constant, }{ }^{\circ} \mathrm{C} \\
& \mathrm{T}_{1}=\text { the flash temperature of the first stage, }{ }^{\circ} \mathrm{C} \\
& \mathrm{T}_{0}=\text { the reservoir temperature, }{ }^{\circ} \mathrm{C}
\end{aligned}
$$

For the second stage:

$$
\left(1-X_{1}\right)\left(\frac{X_{2}}{g_{2}}\right)=\frac{\left(1-X_{1}\right)\left(\Delta i^{\prime}\right)_{2}\left(\Delta i^{\prime \prime}\right)_{2}}{860 r_{2}}
$$


or

$$
\left(1-X_{1}\right)\left(\frac{X_{2}}{g_{2}}\right)=\frac{\left(1-X_{1}\right)\left(C_{1} K_{1}\right)\left(T_{1}-T_{2}\right)\left(T_{2}-T_{3}\right)}{860 r_{2}}
$$

where:

$$
\begin{aligned}
& \mathrm{C}_{1} \mathrm{~K}_{1}=\text { constants or parameters } \\
& \mathrm{T}_{2}=\text { the flash temperature of the second stage, }{ }^{\circ} \mathrm{C}
\end{aligned}
$$

Therefore, from equations $(4.15)$ and $(4.16)$, we get

$$
E_{T}=\left[\frac{C_{0} K_{0}\left(T_{0}-T_{1}\right)\left(T_{1}-T_{3}\right)}{860 r_{1}}+\frac{\left(1-X_{1}\right)\left(C_{1} K_{1}\left(T_{1}-T_{2}\right)\left(T_{2}-T_{3}\right)\right.}{860 r_{2}}\right]
$$

Equation (4.17) shows the effect of the variables $T_{1}$ and $T_{2}$ on the total exergy performed by the double-flash processes. If this quantity $\mathrm{E}_{\mathrm{T}}$ defined in equation (4.17) is to be a maximum, then the partial derivatives with respect to $\mathrm{T}_{1}$ and $\mathrm{T}_{2}$ must be equal to zero. First, let us, to the first approximation, as sume that $\left(1-\mathrm{X}_{1}\right)=1, \mathrm{C}_{\mathrm{O}} \mathrm{K}_{\mathrm{O}}=$ $\mathrm{C}_{1} \mathrm{~K}_{1}=\mathrm{CK}$, and $\mathrm{r}_{1}=\mathrm{r}_{2}=\mathrm{r}$, then we have

$$
E_{T}=\left[\frac{C K\left(T_{0}-T_{1}\right)\left(T_{1}-T_{2}\right)}{860 r}+(1) \frac{C K\left(T_{1}-T_{2}\right)\left(T_{2}-T_{3}\right)}{860 r}\right]
$$

At the optimum conditions the partial derivatives of equation (4.18) must be equal to zero.

$$
\frac{\partial E_{T}}{\partial T_{1}}=\frac{C K}{860 r}\left(\left(T_{0}-2 T_{1}+T_{3}\right)+\left(T_{2}-T_{3}\right)=0\right.
$$

and

$$
\frac{\partial E_{T}}{\partial T_{2}}=\frac{C K}{860 r}\left(T_{1}-2 T_{2}+T_{3}\right)=0 \text {. }
$$


Solving simultaneously for the optimum values of $T_{1}$ and $T_{2}$,

$$
\begin{aligned}
& T_{\text {lopt. }}=\frac{1}{3}\left(2 T_{0}-T_{3}\right) \\
& T_{\text {2opt. }}=\frac{1}{3}\left(2 T_{3}+T_{0}\right)
\end{aligned}
$$

The quantities $T_{1}$ and $T_{2}$ defined in equations (4.19) and (4.20) represent the approximate first order temperature optima. In order to obtain more exact optima for $T_{1}$ and $T_{2}$, further investigation must be carried on. We introduce equation (4.18) in the following form

$$
E_{T}=\frac{C_{0} K_{o}}{860 r_{1}}\left[\left(\left(T_{0}-T_{1}\right)\left(T_{1}-T_{3}\right)+\left(1-X_{1}\right) \frac{C_{1} K_{1}}{C_{0} K_{0}} \frac{r_{1}}{r_{2}}\left(T_{1}-T_{2}\right)\left(T_{2}-T_{3}\right)\right]\right.
$$

If we let

$$
A=\left(1-X_{1}\right) \frac{C_{1} K_{1}}{C_{0} K_{0}} \frac{r_{1}}{r_{2}}
$$

then equation $(4.21)$ becomes

$$
E_{T}=\frac{C_{0} K}{860 r_{1}}\left[\left(T_{0}-T_{1}\right)\left(T_{1}-T_{3}\right)+\left(T_{1}-T_{2}\right)\left(T_{2}-T_{3}\right) A\right]
$$

Where $A$ is a correction factor, which is approximately constant.

Again, at the optimum conditions the partial derivatives of the quantity $E_{T}$ defined in equation (4.22) must be equal to zero;

$$
\frac{\partial E_{T}}{\partial T_{1}}=\frac{C_{0} K_{0}}{860 r_{1}}\left[\left(T_{0}-2 T_{1}+T_{3}\right)+A\left(T_{2}-T_{3}\right)\right]=0
$$




$$
\frac{\partial E_{T}}{\partial T_{2}}=\frac{C_{0} K_{0}}{860 r_{1}}\left[\left(A\left(T_{1}-2 T_{2}+T_{3}\right)\right]=0 .\right.
$$

Solving simultaneously for the optimum $T_{1}$ and $T_{2}$,

$$
\begin{aligned}
& \mathrm{T}_{\text {lopt, }}=\frac{1}{4-\mathrm{A}}\left(2 \mathrm{~T}_{\mathrm{o}}+(2-\mathrm{A}) \mathrm{T}_{3}\right) \\
& \mathrm{T}_{\text {2opt. }}=\frac{1}{4-\mathrm{A}}\left(\mathrm{T}_{\mathrm{o}}+(3-\mathrm{A}) \mathrm{T}_{3}\right)
\end{aligned}
$$

The quantities $T_{1}$ and $T_{2}$ defined in equations (4.23) and (4.24) are more exact optimum flash temperatures for a doubleflash geothermal power plant operating on the basis of thermal water from a liquid phase reservoir.

\section{NUMERICAL CALCULATIONS LEADING TO THE OP TIMUM FLASH TEMPERATURES FOR DOUBLE-FLASH POWER CYCLE}

Numerical calculations have been carried out with the help of the first order iterated linear interpolation method. We have relied on the i-s diagram and saturated steam tables (by temperatures) (29) in order to obtain the data necessary for such calculations. In this case, we are in a position to summarize the procedure of calculation as follows:

1. For the first stage, obtain an approximate value of the constants $C_{0}$, and $K_{0}$ from 
$\left(\Delta i^{\prime}\right)_{1}=C_{0}\left(T_{0}-T_{1}\right)$

where

$C_{0}=\frac{\left(\Delta i^{\prime}\right)_{1}}{\left(T_{0}-T_{1}\right)_{1}}$

And

$\left(\Delta \mathrm{i}^{\prime \prime}\right)_{1}=\mathrm{K}_{\mathrm{o}}\left(\mathrm{T}_{1}-\mathrm{T}_{3}\right)_{1}$

where

$K_{0}=\frac{\left(\Delta i^{\prime \prime}\right)_{1}}{T_{1}-T_{3}}$.

Where $T_{1}$ is an approximate optimum flash temperature of the first stage, and $\mathrm{T}_{3}$ is the condensate temperature which is a constant.

2. In the second stage, obtain also, an appropriate value of the constants $C_{1}$ and $K_{1}$ from $\left(\Delta i^{\prime}\right)_{2}=C_{1}\left(T_{1}-T_{2}\right)_{2}$

where

$C_{1}=\frac{\left(\Delta \mathrm{i}^{\prime}\right)_{2}}{\left(\mathrm{~T}_{1}-\mathrm{T}_{2}\right)_{2}}$

and

$\left(\Delta i^{\prime \prime}\right)_{2}=K_{1}\left(T_{2}-T_{3}\right)_{2}$ 
where

$K_{1}=\frac{\left(\Delta i^{\prime \prime}\right)_{2}}{\left(T_{2}-T_{3}\right)_{2}}$

Where $\mathrm{T}_{2}$ is an approximate optimum flash temperature in the second stage, and it is defined by equation $\left(4.20 \%, T_{3}\right.$ is the condensate temperature which is a constant.

3. Obtain the correction factor $\mathrm{A}$, by the formula

$$
A=\left(1-X_{1}\right) \frac{C_{1} K_{1}}{C_{0} K_{0}} \frac{r_{1}}{r_{2}} \text {, }
$$

and

$x_{1}=\frac{\left(\Delta i^{\prime}\right) 1}{r_{1}}$

Where $r_{1}$ and $r_{2}$ are the latent heats of evaporation for the working fluid in the first and second stages respectively.

4. Calculate the exact temperature optima for the first stage and second stage processes by using the following formulas which have been defined by equations $(4.23)$ and $(4.24)$,

$\mathrm{T}_{\text {lopt. }}=\frac{1}{4-\mathrm{A}}\left(2 \mathrm{~T}_{\mathrm{o}}+(2-\mathrm{A}) \mathrm{T}_{3}\right)$

and 
5. Return to step 1 and repeat the procedure for other cases and so on, otherwise stop.

The procedure has been programmed and the experimental program and numerical examples for 10 different cases at different temperatures are given in the Appendices. 


\section{ECONOMIC OPTIMIZATION FOR A GEOTHERMAL} HEATING SYSTEM

In Chapter IV we considered a special kind of optimization problem, one involving the finding of optimum operating temperatures (flash temperatures) for a geothermal power plant of a single and double flash process. In this chapter we consider an economic optimization problem connected with heating systems as a nother important application of geothermal energy.

The current development in the utilization of geothermal energy for industrial space heating is of economic importance where this source of energy is available and can be produced at low cost. In Iceland for example, the entire city of Reykjavik, with a popula tion of 90,000 people, lives in houses heated by natural heat produced from various thermal areas at a cost ranging between $\$ 1.0-2.0 /$ Gcal (Gcal = Gigacalory $=10^{9}$ cal) $(11,12)$.

As indicated by Bodvarsson, Zoega, and Sigurdsson (11, $12,30)$, the general design of the heating systems in Reykjavik, Iceland is based on the following unit operation process:

1. Geothermal water produced from the local resource has a base temperature between $87^{\circ} \mathrm{C}$ and $142^{\circ} \mathrm{C}$. 
2. Geothermal water is applied directly to household radiators.

3. 85 percent of the district heating system supplies thermal water at a temperature of 75 to $80^{\circ} \mathrm{C}$ through a single-pipe system.

4. 15 percent is designed as a double-pipe return system where the thermal water is circulated.

5. The total heating cost based on geothermal energy is approximately $\$ 4 / G$ cal, and this is only about 60 percent of the heating cost based on oil (11).

Space heating using geothermal water also has been in practice for many years in Boise, Idaho, U.S.A., and Klamath Falls, Oregon, U.S.A. In New Zealand, major developments in this aspect have been initiated (25).

\section{GEOTHERMAL HEA TING SYSTEM}

In this study, the geothermal heating system considered is one in which hot borehole water is pumped into a space at a fixed temperature. The water provides heat by flowing through radiators, convectors, or other suitable heat transfer devices. The system discussed here has a water temperature $\leq 100^{\circ} \mathrm{C}$ and is classified as a low temperature geothermal system. Simplified flow-diagram for this type of geothermal heating system is shown in Figure 10 . 


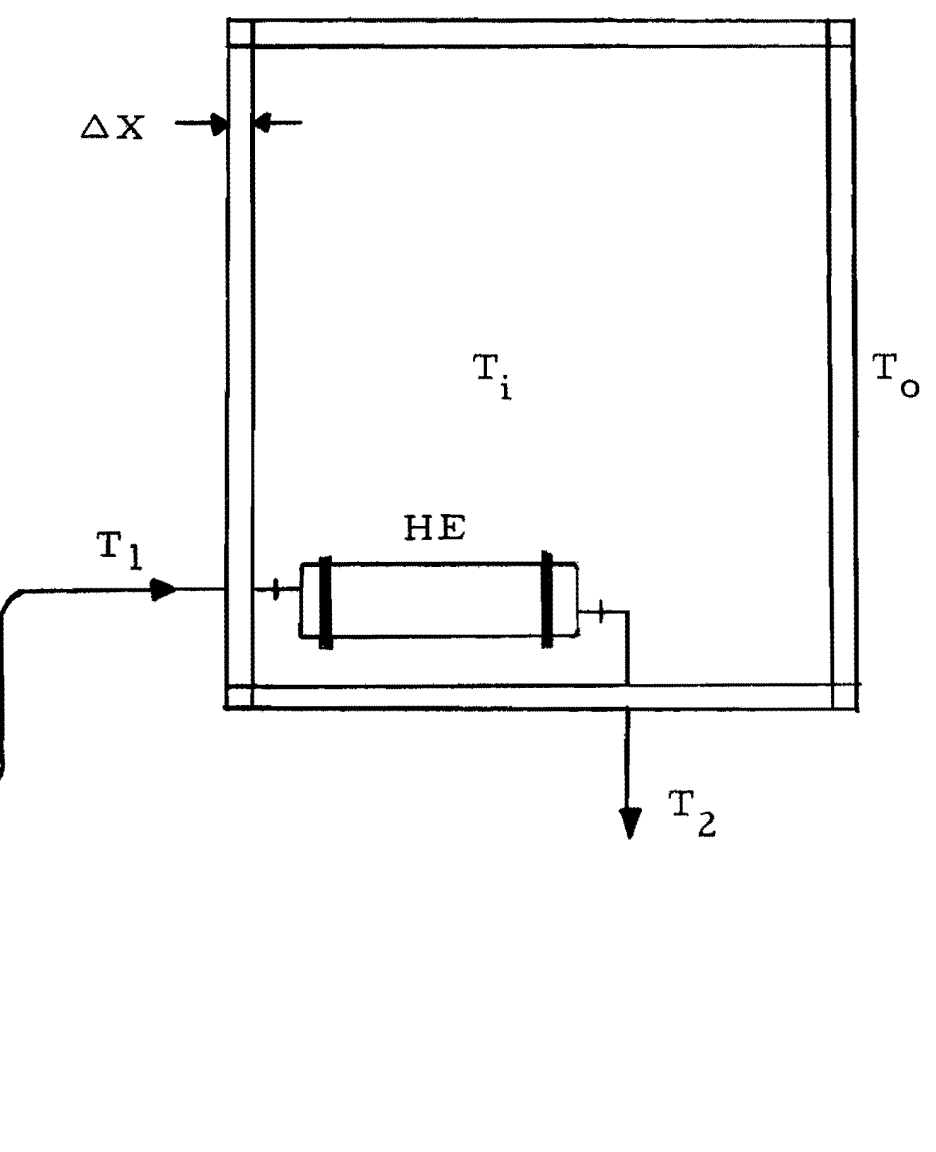

Figure 10. Simplified sketch of a geothermal heating system. ( $\mathrm{B}=$ bor ehole $), T_{1}=$ inlet temperature, $\left(T_{2}=\right.$ outlet temperature,

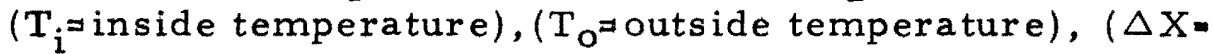
thickness of insulation), and ( $\mathrm{HE}=$ heat exchange). 
The design of most heating systems of this type is based on the assumption that the following variables are known:

1. Available mass flow of thermal water.

2. Inlet temperature of thermal water.

With this information, certain other process conditions have to be considered:

1. Heat transfer area, or in other words, the area of heat exchanger.

2. Type and thickness of wall insulation.

\section{SYSTEM OPTIMIZATION}

An optimum economic design for a house-heating system operating on the basis of thermal water at low-temperature is based on the conditions of least total cost. The problem involves the determination of these optimum conditions at which the sum of the capital and operating costs for such systems is a minimum.

In general, increased flow velocity of thermal water results in a larger heat transfer coefficient in the heat exchanger, and consequently, less heat transfer area resulting in lower exchanger capital cost for a given rate of heat transfer. Also, an increased temperature range utilization will lower the operating cost but enhance the heat exchanger capital cost. On the other hand, increased thickness of insulation causes a decrease in heat loss 
through the walls but greater insulating capital cost. The basic problem therefore, is to minimize the sum of the variable costs for this heating system and its operation.

The important variable costs are the cost of insulation materials, the cost of the thermal fluid, and the cost of the heat exchanger. The total cost, therefore, can be represented by the following equation:

$$
C_{T}=r_{1} C_{1} \Delta X A+C_{2} m+r_{3} C_{3} a
$$

or

$$
\frac{C_{T}}{A}=r_{1} C_{1} \Delta X+\frac{C_{2} m}{A}+\frac{r_{3} C_{3} a}{A}
$$

Where:

$$
\begin{aligned}
& \frac{C_{T}}{A}=\text { the total annual variable cost for the system, } \\
& \quad \$ / \text { year }-\mathrm{m}^{2} \\
& C_{1}=\text { the unit cost of insulation, } \$ / \mathrm{m}^{3} \\
& C_{2}=\text { the unit cost of thermal fluid, } \$ / \text { metric ton }(\mathrm{mt}) \\
& C_{3}=\text { the unit cost of heat exchanger installed, } \$ / \mathrm{m}^{2}, \\
& a_{A}=\text { the surface area of the heat exchanger, } \mathrm{m}^{2} \\
& \mathrm{r}_{1} \text { and } \mathrm{r}_{2}=\text { the surface area of the space, } \mathrm{m}^{2} \\
& \Delta S=\text { the thickness of insulation, } \mathrm{m} \\
& \mathrm{m}=\text { the mass flow of thermal water, } \mathrm{kg} / \mathrm{sec}
\end{aligned}
$$


The first step in the optimization procedure is to express an equation (5.2) in terms of the fundamental variables $a, m$, and $\Delta X$. The following relationships for the rate of heat transfer on the tota? area of the heat exchanger are

$$
Q_{a}=\text { ha }(\Delta t) \text { in }
$$

or

$$
Q_{a}=h a \frac{\left(T_{1}-T_{i}\right)-\left(T_{2}-T_{i}\right)}{\ln \frac{T_{1}-T_{i}}{T_{2}-T_{i}}}
$$

Where:

$Q_{a}=$ the rate of heat transfer on the total area of the heat exchanger. The subscript a refers to the area of heat exchanger.

$\mathrm{h}=$ the coefficient of heat transfer in the heat exchanger, Watt $/ \mathrm{m}^{2}-{ }^{\circ} \mathrm{C}$

$(\Delta t) \ln =$ the logarithmic mean temperature difference

$T_{1}=$ the inlet temperature of hot water to the system, ${ }^{\circ} \mathrm{C}$

$\mathrm{T}_{2}=$ the outlet temperature of the system, ${ }^{\circ} \mathrm{C}$

$T_{i}=$ the inside room temperature (fixed), ${ }^{\circ} \mathrm{C}$

The other significant factor affecting the optimum design of the system is the heat provided by the fluid passing through the heat exchanger. This is shown by the following relationships 


$$
Q_{f}=m S\left(T_{1}-T_{i}\right)
$$

Where:

$$
\begin{aligned}
& Q_{f}= \text { the rate of heat loss by the fluid passing through } \\
& \text { the exchanger. The subscript f refers to the hot } \\
& \text { fluid. } \\
& S=\text { the specific heat of fluid, Joul } / \mathrm{kg}-{ }^{\circ} \mathrm{C}
\end{aligned}
$$

Also, the rate at which heat flows out of the space, in other words, the heat lost by the walls, depends on the inside temperature $T_{i}$, outside temperature $T_{0}$, and the insulating properties of the wall. Floor, ceiling, cracks in the wall, windows, etc., in this case are assumed as negligible. If the temperature difference $\left(T_{i}-T_{0}\right)$ is large, the rate at which heat is lost out of the space will be correspondingly large. In fact, the rate at which heat lost through the wall can be represented by the following relationship

$$
Q_{w}=\frac{A K\left(T_{i}-T_{0}\right)}{\Delta X}
$$

Where:

$$
\begin{aligned}
\mathrm{Q}_{\mathrm{w}}= & \text { the rate of heat loss through the wall, and the } \\
& \text { subscript } \mathrm{w} \text { refers to the wall } \\
\mathrm{K}= & \text { the coefficient of thermal conductivity of the } \\
& \text { insulating material, } \frac{\text { watt }}{\mathrm{m}-{ }^{\circ} \mathrm{C}} \\
\mathrm{T}_{\mathrm{O}}= & \text { the outside temperature }{ }^{\circ} \mathrm{C}
\end{aligned}
$$


Combining equations (5.3) and (5.5) and dropping the subscripts of $q$, since $Q_{a}=Q_{w}$, gives

$$
a=\frac{\operatorname{AK}\left(T_{i}-T_{0}\right) \ln \cdot \frac{T_{1}-T_{i}}{T_{2}-T_{i}}}{h \Delta X\left(T_{1}-T_{2}\right)}
$$

Similarly, combine equations (5.4) and (.5.5), gives

$$
m=\frac{A K\left(T_{i}-T_{0}\right)}{\Delta X S\left(T_{1}-T_{2}\right)}
$$

By substituting the quantities of $a$ and $m$ defined by equations (5.6) and $(5.7)$ in equation ( 5.2$)$, the cost function becomes

$$
\frac{C_{T}}{A}=r_{1} C_{1} \Delta X+\frac{\tau C \frac{K}{2}\left(T_{i}-T_{0}\right)}{S \Delta X\left(T_{1}-T_{2}\right)}+\frac{r_{3} C_{3} K\left(T_{i}-T_{0}\right) \ln \frac{T_{1}-T_{i}}{T_{2}-T_{i}}}{h \Delta X\left(T_{1}-T_{2}\right)},
$$

where:

$$
\begin{aligned}
& \tau=\text { a constant which is equal to } 3.2 \times 10^{7} \frac{\mathrm{sec}}{\text { year }}, \\
& \text { assuming the load factor } \mathrm{Q} \text { is one year, } \\
& \text { since } \tau \text { (time) }=3.2 \times 10^{7} \mathrm{Q} .
\end{aligned}
$$

Minimize equation $(5.8)$ with respect to $\Delta X$ which gives

$$
\frac{d \frac{C_{T}}{A}}{d \Delta X}=r_{1} C_{1}-\frac{\tau C_{2} K\left(T_{i}-T_{0}\right)}{S(\Delta X)^{2}\left(T_{1}-T_{2}\right)}-\frac{r_{3} C_{3} K\left(T_{1}-T_{0}\right) \ln \frac{T_{1}-T_{i}}{T_{2}-T_{i}}}{h(\Delta X)^{2}\left(T_{1}-T_{2}\right)}=0
$$

and hence for a constant $T_{2}$, 
$(\Delta X)_{\text {opt. }}=\left[\frac{\mathrm{K}\left(\mathrm{T}_{\mathrm{i}}-\mathrm{T}_{0}\right)}{\mathrm{r}_{1} \mathrm{C}_{1}} \frac{\tau \mathrm{C}_{2}}{\mathrm{~S}\left(\mathrm{~T}_{1}-\mathrm{T}_{2}\right)}+\frac{\mathrm{r}_{3} \mathrm{C}_{3} \ln \frac{\mathrm{T}_{1}-\mathrm{T}_{\mathrm{i}}}{\mathrm{T}-\mathrm{T}_{\mathrm{i}}}}{\mathrm{h}\left(\mathrm{T}_{1}-\mathrm{T}_{2}\right)}\right]^{1 / 2}$

Inserting this value into the cost function above, equation (5.8), and compute the total cost as a function of single variable $T_{2^{\circ}}$. Do this for several values of $\mathrm{T}_{2}$ and plot the values of $\mathrm{C}$ against $\mathrm{T}_{2}$ in order to find the minimum total cost for this system.

Numerical calculations leading to the optimum cost for this geothermal heating system have been carried out applying the following data:

The unit cost $\left(C_{1}\right)$ of insulation material (fiber-glass) is $\$ 10 /$ cubic meter.

The unit cost $\left(\mathrm{C}_{2}\right)$ of the thermal fluid combined with the pumping cost is assumed to be $\geq$ to $\$ 0.05 /$ metric ton.

The unit cost $\left(\mathrm{C}_{3}\right)$ of heating surface area of the heat exchanger (radiator) is $\$ 5.0 /$ square meter.

The rate of interests $\left(r_{1}, r_{3}\right)$ are assumed to be 10 percent annually.

The overall coefficient of heat transfer (h), in the heat exchanger is 10 watt $/ \mathrm{m}^{2}-{ }^{\circ} \mathrm{C}$.

The coefficient of thermal conductivity $(K)$, of the insulation material is 0.08 watt $/ \mathrm{m}-{ }^{\circ} \mathrm{C}$. 
The specific heat (S) of the thermal fluid is $4200 \mathrm{Joule} / \mathrm{kg}-{ }^{\circ} \mathrm{C}$, which is equal to $4.2 \times 10^{6} \mathrm{Joule} / \mathrm{met}$ ic ton.

The inlet temperature of the fluid to the system is $100^{\circ} \mathrm{C}$ and it is fixed.

The inside room temperature is $20^{\circ} \mathrm{C}$, as sumed fixed. The outside room temperature is $-10^{\circ} \mathrm{C}$, also assumed fixed.

The procedure of optimization for this system has been programmed and the experimental program and numerical examples applying the above data for 12 different cases of temperature $\mathrm{T}_{2}$ (outlet temperature) are given in the Appendices. Figure 11 presents the graphical method of the economical optima for this system having a constant inlet temperature of hot water at $100^{\circ} \mathrm{C}$. In this case the minimum total annual cost is $\$ 0.2572$ per meter square, when the temperature $T_{2}$ of the waste thermal water (outlet temperature) is $28^{\circ} \mathrm{C}$ and an optimum thickness of insulation of the wall is 0.126 meter.

The preceding analysis clearly neglects a number of factors that may have an influence on the economical optima of such a geothermal heating system, such as cost of piping, cost of pumping equipment, taxes, etc. 


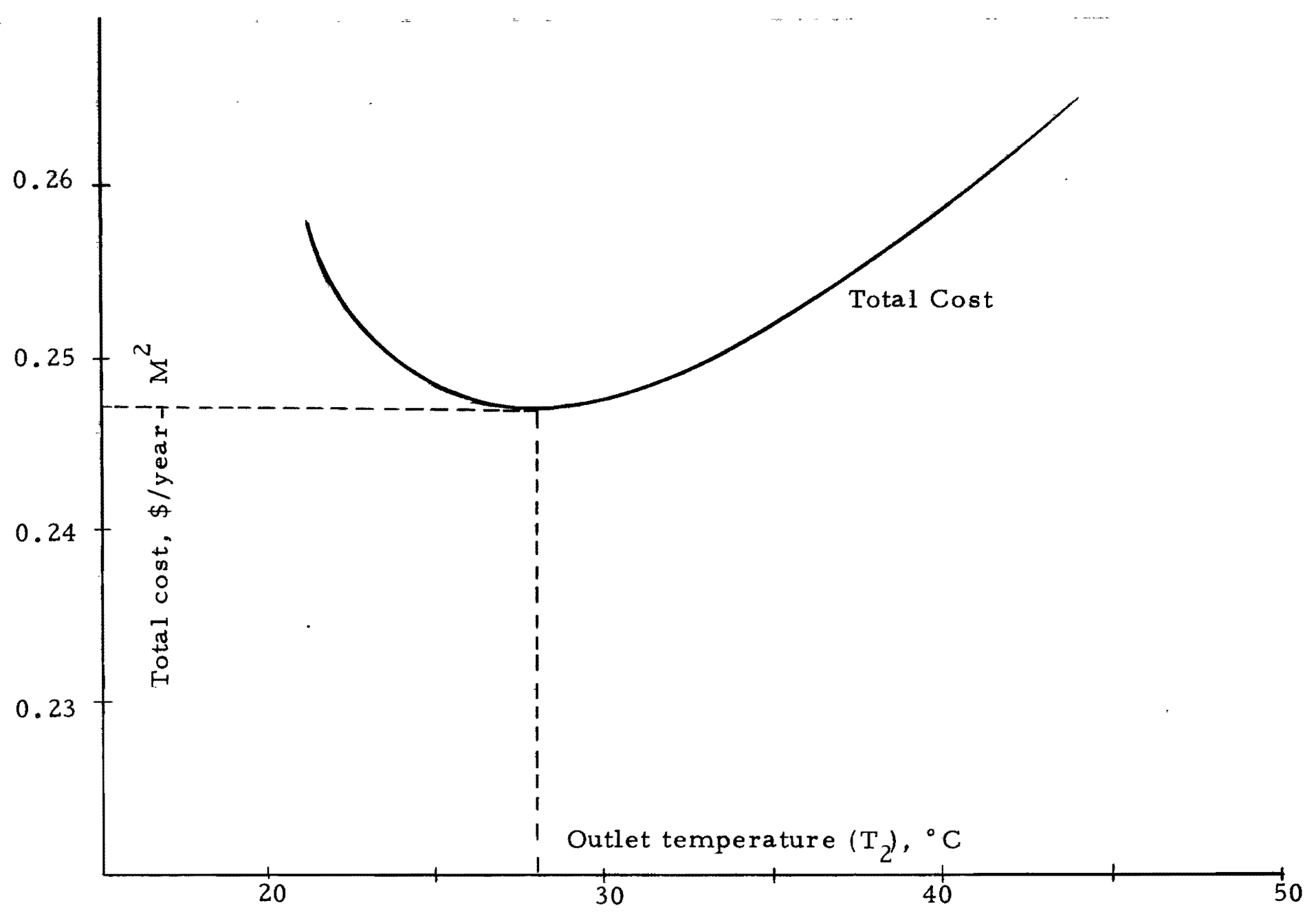

Figure 11. Determination of the optimum cost for a geothermal heating system 


\section{CONCLUSIONS AND RECOMMENDATIONS}

The present investigation of optimality in geothermal engineering has led to the following conclusions and remarks:

1. In the case of single-flash cycle, results from both the graphical (given in Table IV) and analytical methods using first order approximation where the latent heat of evaporation, $r_{1}\left(T_{1}\right)$, is assumed constant, indicate es sentially the same theoretical optimum flash temperature. This shows that the first order linear estimation was a valid assumption for the approximation.

2. The correction factor resulting from the second order approximation improves the value of the optimum temperature by about 1.5 percent, this is due to the combined effect of the parameters $\gamma$ and $\beta$, which represent the inclusion of non-linear heat capacity terms and temperature sensitive latent heat. Therefore, higher-order approximation may be required for obtaining higher values of correction factors which lead probably to a more exact optimum flash temperature. Higher order correction factors would obviously 
marginally improve the accuracy of the results, but with unnecessarily large effort. However, such an effort might be the subject of a more in-depth study 。

3. In the case of double-flash process, temperature optima were obtained by the analytical method using a first order approximation. This process provided the main improvement over the single-flash as far as power output is concerned. An additional improvement in the optimization could be made by using a second order approximation method for this type of power plants .

4. From Figure 11 we can conclude that the minimum annual cost for the space heating system is obtained by keeping the outlet temperature $\mathrm{T}_{2}$ at $28^{\circ} \mathrm{C}$. Space heating system is, therefore, heavily influenced by the insulating cost, and the heating cost is by no means a linear function of the insulation cost. 


\section{R EFER ENCES}

1. Anderson, J.H., "A Vapor Turbine Geothermal Power Plant," Resources and Transportation Division: Energy Section, UN, New York, 1970.

2. Armstead, H.C.H., "Geothermal Power for Non-Base Load Purposes", UNS Pisa, Xl/1, 1970.

3. Bangnea, P., "The Development and Performance of SteamWater Separator for Use on Geothermal Bores, "UNC Rome, G/13, 1961 .

4. Bodvarsson, G., "Some Consideration on the Optimum Production and Use of Geothermal Energy," JOKULL, III, 16 , a'r, 1966.

5. Bodvarsson, G., "Energy and Power of Geothermal Resources," The ORE BIN, Vol.28, No.7, July, 1966.

6. Bodvarsson, G., "The Exploitation of Geothermal Resources in the Present and in the Future", Dept. of Economic and Social Aff., UN, New York.

7. Bodvarsson, G., "An Estimate of the Natural Heat Resources in a Thermal Area in Iceland", UNS Pisa, VII/I, 1970.

8. Bodvarsson, G., "A Study of the Ahuachapan Geothermal Reservoir," UNDP Survey of Geothermal Resources in El-Salvador, June, 1971 .

9. Bodvarsson, G., "Evaluation of Geothermal Prospects and the Objertive of Geothermal Exploration, "Geoexploration, Vol. 8, 1970 .

10. Bodvarsson, G., and D.E. Eggers, "The Exergy of Thermal Water," Geothermics, Vol. 1, No.3, 1972. pp.93-95.

11. Bodvarsson, G., "Utilization of Geothermal Ex́ergy for Heating Purposes and Combined Schemes Involving Power Generation, Heating and/or by-Products," UNC Rome, GR/5, 1961 . 
12. Bodvarsson, G., and J. Zoega, "Production and Distribution of Natural Heat for Domestic and Industrial Heating in Iceland," UNC Rome, G/37, 1961.

13. Chieici, A., "Planning of a Geothermal Power Plant: Technical and Economic Principles," UNC Rome, G/62, 1961.

14. Donato, G., "Natural Steam Power Plants of Larderello," Mech.Engr., Vol. 73, No.9, Sept. 1951, pp. 709-712.

15. Hansen, A., "Thermal Cycles for Geothermal Sites anc? Turbine Installation at the Geysers Power Plant," UNC Rome, G/41, 1961 .

16. Holt, B., A.J.L. Hutchinson and D.H. Cortez," Advanced Binary Cycles for Geothermal Power Generation," Symposium on New Sources of Energy, Univ. of Southern Calif., May 9, 1973.

17. James, R., "Power Station Strategy", UNS Pisa, XI/2, 1970.

18. James, R., "The Economics of the Small Geothermal Power Station," UNS Pisa, XI/121, 1970.

19. James, R., "Larderello and Wairaki Geothermal Power Systems Compared," Chemistry Division, New Zealand Dept. of Sc. and Industrial Res., Wairaki, Jan. 1968.

20. James, R., G.D. McDowell and M.D. Allen, "Flow of SteamWater Mixtures Through a 12 -Inch Diameter Pipeline," UNS Pisa, VIII/4, 1970.

21. James, R., "Factors Controlling Borehole Performance," UNS Pisa, VII/6, 1970.

22. James, J. B. and A. Hawkins, "Engineering Thermodynamics," John Wiley and Sons, Inc., New York, London, 1960.

23. Kaufman, A., "The Economics of Geothermal Power in the U.S.A.," UNS Pisa, X1/11, 1970.

24. Kaufman, A., "Geothermal Power: An Economic Study," IC 8230 , U.S. Dept. of the Interior, Bureau of Mines, 1964 . 
25. Kerr, R.N., R. Bangma, W.L. Cooke, F.G. Furness and G. Vamos, "Recent Development in New Zealand in the Utilization of Geothermal Energy for Heating Pur poses," UNC Rome, G/52, 1961.

26. Muffler, L.J.P. and D.E. White, "Geothermal Energv." The Science Teacher, Vol. 39, No.3, 1972, pp.40-43.

27. Muffler, L.J.P., "Geothermal Resources," U.S. Geol. Survey, 1973.

28. McNitt, J.R., "Exploration and Development of Geothermal Power in California," Calif. Div. of Mines, Mineral Inf. Service, Vol. 13, No.3, 1963.

29. Sushkou, V.V., "Technical Thermodynamics," Noordhoff, Ltd. The Netherlands, 1965.

30. Sigurdsson, H., 'Reykjavik Municipal District Heating Service and Utilization of Geothermal Energy for Domestic Heating, "UNC Rome, G/45, 1960.

31. Villa, F., "Latest Trends in the Design of Geothermal Plants," UNC Rome, G/72, 1961 .

32. White, D.E., L.J.P. Muffler and A.H. Truesdell, "VaporDominated Hydrothermal Systems Compared with Hot-Water System," Econ. Geol., Vol.66, No.1, 1971 , pp $75-97$.

33. Weismantel, G.E., "Geothermal Power Perks Up," Chem. Engr., Nov. 30, 1970, pp 24-25.

34. Wong, C.M., "Geothermal Energy and Desalination: Partners in Progress," UNS Pisa, 1970. 
APPENDICES 
Computer Program for Singular Flash Power Cycle

$90 C$ NUMERICAL CALCULATION LEADINO TO THE OPTIMUM FLASH

95C TEMPERATURE FOR SINGLE-FLASH POHER CYCLE

100 DIMENSION TO $(30), T 1(30), T 2(30), T 3(30)$

110 DIMENSION T4(30),TS (30),DI (30),Da (30)

120 DIRENSION D3 (30),DA(30), RI (30),DR(30)

130 DIMENSION ALPHA $(30)$, GAMAA $(30)$, VITA $(30)$

140 DIMENSION CF $(30)$, TOP (30)

150 REAL $K$

160 PRINT, - INPUT NO. OF VARIABLES"

170 INPUT, $N$

180 PRINT,- INPUT CONSTANTS T3 + T5*

190 INPUT, T $3(1), T S(1)$

200 DO $I \quad I=2, N$

$210 T 3(1)=T 3(1)$

$2201 \mathrm{TS}(1)=\mathrm{TS}(1)$

230 PRINT,-INPUT TO,T $1, T 2, T 4 *$

240 DO $2 I=1, N$

2502 INPUT, TO(I),TI(I),TE(I),T $4(1)$

260 PRINT,-INPUT DI,Da,D3,D4*

270 DO $3 \quad I=1, N$

2803 INPUT $, D I(I), D 2(I), D 3(1), D 4(1)$

290 PRINT, - INPUT RI,DR-

300 DO $4 I=1, N$

3104 INPUT, RI (I),DR(I)

320 DO $13 \quad I=1, N$

330 HO=T $5(I) * R I(I)+D R(I)=T A(I)$

$340 \mathrm{HI}=\mathrm{DQ}(1) /(\mathrm{TO}(1)-\mathrm{TR}(1))$

$350 \mathrm{HE}=\mathrm{DI}(\mathrm{I}) /(\mathrm{TO}(\mathrm{I})-\mathrm{TI}(\mathrm{I}))$

$360 \mathrm{H3}=\mathrm{DA}(1) /(\mathrm{Ta}(\mathrm{I})-\mathrm{T} 3(\mathrm{I}))$

$370 \mathrm{HA}=\mathrm{D} 3(\mathrm{I}) /(\mathrm{T} I(I)-T 3(1))$

$380 \mathrm{H} 5=\mathrm{T} 2(1)-\mathrm{T}_{1}(1)$

$390 H 6=T O(I)+T_{1}(I)$

$400 \mathrm{HT}=\mathrm{TI}(\mathrm{I})+\mathrm{T} 3(\mathrm{I})$

$410 \quad B=(H 1-H 2) / H 5$

$420 \quad A=H 2-B * H 6$

$430 \mathrm{~S}=(\mathrm{R3}-\mathrm{HA}) / \mathrm{HS}$

$440 \quad K=\mathrm{H} 4-\mathrm{S}=\mathrm{H7}$

450 ALPHA (I) $=B / A$

460 GAMMA $(I)=S / K$

$\triangle 70$ VITACI $)=D R(I) / H O$

$480 \mathrm{CF}(1)=((\mathrm{VITA}(I)+\operatorname{GAMMA}(1)) *((T O(I)-T 3(1)) * * 8)) / 8.0$

$490 \mathrm{H} 8=(\mathrm{TO}(1)+\mathrm{T} 3(1)) / 2.0$

50013 TOP $(1)=\mathrm{H} 8+\mathrm{CF}(1)$

510 PRINT 61

58061 FORMAT $(/ /, 1 X,-$ SECOND ORDER APPROXIMATION FOR SINGLE

525 + FLASH PROCESSES-, /1)

530 PRINT 17

54017 FORMAT ( $7 X, 2 H T 0,11 X, 5$ HALPHA, 10X, 4HVITA, 9X, 5HGAMMA)

550 PRINT 62

56062 FORMAT $(/ /)$

570 DO $16 \quad I=1, N$

58016 PRINT 27,TO(I),ALPHA(I),VITA(I),BAMMA(I)

59027 FORMAT $(1 X, 4(E \mid 4 \cdot 3))$

600 PRINT 62

610 PRINT 37

62037 FORMAT $(/, 12 \mathrm{X}, 2 \mathrm{HCF}, 11 \mathrm{X}, 9$ HOPT IMUM $\mathrm{T})$

630 PRINT 62

640 DO $26 I=1, N$

65026 PRINT 47,CF (I),TOP(I)

66047 FORMAT $(1 X, 2(E 14.3))$

670 END 
To

\begin{tabular}{|c|c|}
\hline 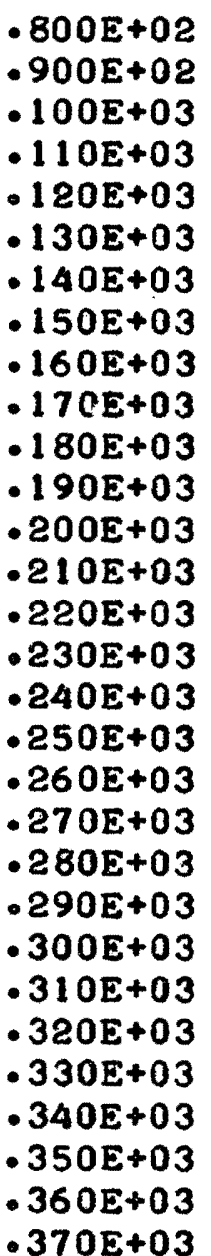 & $\begin{array}{l}.808 E-04 \\
.843 E-04 \\
.111 E-03 \\
.114 E-03 \\
.185 E-03 \\
.153 E-03 \\
.117 E-03 \\
.216 E-03 \\
.264 E-03 \\
.222 E-03 \\
.334 E-03 \\
.347 E-03 \\
.383 E-03 \\
.464 E-03 \\
.398 E-03 \\
.485 E-03 \\
.505 E-03 \\
.538 E-03 \\
.657 E-03 \\
.720 E-03 \\
.867 E-03 \\
.964 E-03 \\
.108 E-02 \\
.124 E-02 \\
.148 E-02 \\
.181 E-02 \\
.233 E-02 \\
.327 E-02 \\
.546 E-02 \\
.564 E-01\end{array}$ \\
\hline
\end{tabular}

VITA

$.978 \mathrm{E}-03$ $.100 E-02$ -101E-02 $.102 E-02$ 103E-02

$.103 E-02$

$.105 E-02$

105E-02

$107 E-02$

-109E-02

$.109 E-02$

-113E-02

. $113 E-02$

-113E-02

- $116 \mathrm{E}-02$

- $115 \mathrm{E}-02$

- $118 \mathrm{E}-02$

- 121E-02

- $122 E-02$

- 124E-02

- 125E-02

- $128 E-02$

- $130 \mathrm{E}-02$

- $132 E-02$

- $135 E-02$

- $137 \mathrm{E}-02$

-140E-02

-143E-02

-146E-02

-149E-02
GAMMA

-.499E-02

-.439E-02

-.338E-02

-. $317 \mathrm{E}-02$

- 243E-02

-.232E-02

$-118 E-02$

- 179E-02

-.166E-02

- $217 \mathrm{E}-02$

$-187 \mathrm{E}-02$

- 189E-02

-.192E-02

$-193 E-02$

$-.214 E-02$

-.197E-02

- 1 184E-02

-.164E-02

-.156E-02

-.160E-02

$-156 E-02$

-.167E-02

- 163E-02

-.158E-02

-.166E-02

- 157E-02

-.157E-02

-.157E-02

-.150E-02

- 150E-02
CF

$-.451 E+00$

$-.678 E+00$

-.741E+00

$-.968 \mathrm{E}+00$

- $854 E+00$

$-.103 E+01$

$-.136 E+00$

$-.914 E+00$

$-.894 E+00$

$-.195 E+01$

$-.165 E+01$

- 185E+01

- $820 \mathrm{E}+01$

$-.255 E+01$

-.355E+01

- $334 E+01$

- $298 \mathrm{E}+01$

- $213 \mathrm{E}+01$

$-.186 \mathrm{E}+01$

$-.218 E+01$

$-.200 E+01$

$-.284 E+01$

-.261E+01

$-.215 \mathrm{E}+01$

-.283E+01

- 195E+01

-.182E+01

-.164E+01

$-.472 E+00$

$-.188 E+00$

\section{OPTIMUM T}

.645E+02 $.693 E+02$

-743E+02

-790E+02

$.841 E+02$

.890E+02

$.949 E+02$

. $991 E+02$

$.104 E+03$

- $108 E+03$

- $113 E+03$

- $118 \mathrm{E}+03$

- 123E+03

- $127 \mathrm{E}+03$

- $131 E+03$

- $137 \mathrm{E}+03$

-142E+03

- $1485+03$

$-153 E+03$

- $158 E+03$

- $163 E+03$

- $167 \mathrm{E}+03$

- $172 E+03$

- $178 \mathrm{E}+03$

- $182 \mathrm{E}+03$

- $188 \mathrm{E}+03$

- $193 E+03$

- 198E+03

- $205 E+03$

- $210 E+03$ 
APPENDIX II

First Order Approximation for Double Flash Power Cycle

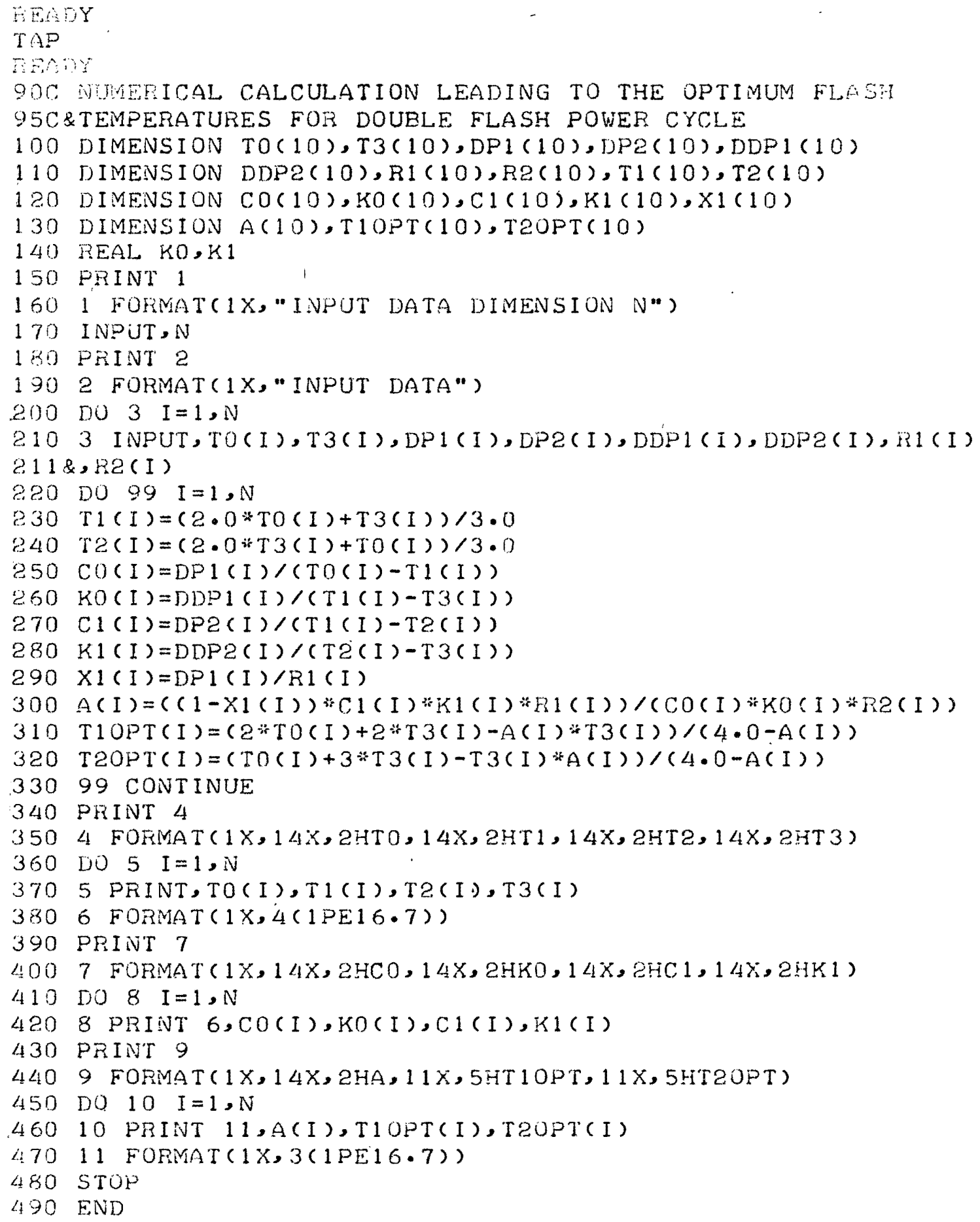


INWI DATA DIMENSION N? 10

INPUE DATA?80.00,50.00,10.02,9.99,31.00,18.00,557.40,563.30

$2110 \cdot 00,50 \cdot 00,20 \cdot 14,20 \cdot 05,62 \cdot 00,31 \cdot 00,545 \cdot 10,557 \cdot 40$

$? 140 \cdot 00,50 \cdot 00,30 \cdot 48,30 \cdot 17,91 \cdot 00,48 \cdot 00,532 \cdot 40,551 \cdot 30$

$2170 \cdot 00,50 \cdot 00,41 \cdot 30,40 \cdot 42,115 \cdot 00,62 \cdot 00,518 \cdot 60,545 \cdot 10$

$2.000 \cdot 00,50 \cdot 00,52 \cdot 50,50 \cdot 86,135 \cdot 00,78 \cdot 00,504 \cdot 60,538 \cdot 90$

$2231,00,50 \cdot 00,64 \cdot 70,61, \ldots .58,155 \cdot 00,91 \cdot 00,489 \cdot 20,532 \cdot 40$

$760 \cdot 00,50 \cdot 00,78 \cdot 20,72 \cdot 50,173 \cdot 00,103 \cdot 00,472 \cdot 50,525 \cdot 70$

$2290 \cdot 00,50 \cdot 00,93 \cdot 70,83 \cdot 90,185 \cdot 00,115 \cdot 00,454 \cdot 00,518 \cdot 60$

$? 320 \cdot 00,50 \cdot 00,112 \cdot 60,95 \cdot 80,200 \cdot 00,125 \cdot 00,433.30,511.90$

$3350 \cdot 01,50 \cdot 00,139 \cdot 70,108 \cdot 30,211 \cdot 00,135 \cdot 00,409 \cdot 80,504 \cdot 60$

To

$8 \cdot 0000000 E+01$

$1 \cdot 1000000 E+02$

$1.4000000 \mathrm{E}+02$

$1 \cdot 7000000 \mathrm{E}+02$

$2 \cdot 0000000 E+02$

2. $3000000 E+02$

$2 \cdot 6,000000 E+02$

$2 \cdot 9000000 E+02$

$3.2000000 E+02$

$3 \cdot 5000000 E+02$

$\mathrm{CO}$

$1.0020000 E+00$

$1.0070000 \mathrm{E}+.00$

1. $0160000 E+00$

$1.0325000 E+00$

$1.0520000 E+00$

$1.0783333 \mathrm{E}+00$

$1.1171429 E+00$

$1.1712500 \mathrm{E}+00$

$1.2511111 \mathrm{E}+00$

1.3970000E+OO

$A$,

$1 \cdot 1250912 \mathrm{E}+00$

$9.3759257 \mathrm{E}-01$

9.5068511E-01

$9 \cdot 2402847 \mathrm{E}-01$

$9.3715558 E-01$

$3.9107598 \mathrm{E}-01$

$8.2802067 \mathrm{E}-01$

$7.7341080 \mathrm{E}-01$

$6.6627108 E-01$

$5.3099532 \mathrm{E}-01$
$T 1$

$7.0000000 E+01$

$9.0000000 E+01$

$1.1000000 E+02$

1. $3000000 E+02$

1.5000000E+02

$1.7000000 E+02$

$1.9000000 \mathrm{E}+02$

$2.1000000 E+02$

$2.3000000 E+02$

$2.5000000 E+02$ KO

$1 \cdot 5500000 \mathrm{E}+00$

1. $5500000 \mathrm{E}+00$

$1.5166667 \mathrm{E}+00$

$1.4375000 E+00$

$1.3500000 E+00$

$1.2916667 \mathrm{E}+00$

$1.2357143 E+00$

$1.1562500 \mathrm{E}+00$

$1.1111111 \mathrm{E}+00$

$1.0550000 E+00$

TIUPT

$7.0870227 E+01$

$8.9184858 \mathrm{E}+01$

$1.0902965 \mathrm{E}+02$

$1.2802413 \mathrm{E}+02$

$1.4794817 \mathrm{E}+02$

$1.6579569 \mathrm{E}+02$

$1.8240944 E+02$

$1.9876390 \mathrm{E}+0 \mathrm{c}$

2.11990\%85+02

2. $2296027 \mathrm{E}+02$
T2

$6.0000000 E+01$

$7 \cdot 0000000 \mathrm{E}+01$

$8.0000000 E+01$

$9.0000000 E+01$

$1.0000000 E+02$

$1.1000000 E+02$

1.2000000E+02

1. $3000000 E+02$

1. $4000000 E+02$

1. $5000000 E+02$

C 1

9.9900000E-01

$1.0025000 E+00$

1. $0056667 \mathrm{E}+00$

$1.0105000 \mathrm{E}+00$

$1.0172000 E+00$

$1.0263333 E+00$

$1.0357143 E+00$

1. $0487500 \mathrm{E}+00$

$1.0644445 E+00$

1. $0830000 E+00$

TROPT

$6.0435113 E+01$

$6 \cdot 9592428 E+01$

$7 \cdot 9514827 \mathrm{E}+01$

$8.9012064 E+01$

$9.8974083 E+01$

$1.0789784 \mathrm{E}+0$ ?

$1.1620472 \mathrm{E}+02$

$1.2438195 \mathrm{E}+02$

$1 \cdot 3099039 \mathrm{E}+02$

$1.3648014 \mathrm{E}+02$
T3

$5.0000000 E+01$

5.0000000E+01

$5.0000000 E+01$

$5.0000000 E+01$

5. $0000000 E+01$

5. $0000000 E+01$

5.0000000E+01

5. $0000000 \mathrm{E}+01$

$5.0000000 E+01$

5. $0000000 E+01$

$\mathrm{K} 1$

$1.8000000 E+00$

1. $5500000 E+00$

$1.6000000 E+00$

1. $5500000 \mathrm{E}+00$

$1.5600000 E+00$

$1.5166667 \mathrm{E}+00$

$1.4714286 \mathrm{E}+00$

$1.4375000 E+00$

$1 \cdot 3888889 E+00$

1. $3500000 \mathrm{E}+00$

PHOGIAM STOP AT 480 
Numerical Calculation Leading to the Optimum Cost

for a Geothermal Heating System

READY

TAP

READY

90C NUMERICAL CALCULATION LEADING TO THE OPTIMUM COST FOR A

95C GEOTHERMAL HEATING SYSTEM

100 DIMENSION TI(12),Ta(12),TIN(12),TOUT (12)

110 DIMENSION RI $(12), R_{3}(12), C 1(12), C 2(12), C 3(12)$

120 DIMENSION $H(12), K(12), S(12), D(12)$

130 DIMENSION E(12),F(12),DELX(12),CT(12)

140 REAL $K$

150 PRINT, "INPUT NO. OF VARIABLES"

160 INPUT, N

170 PRINT, - INPUT CONSTANTS $T 1+T I N+T O U T+R I+R 3=$

$180 \quad I=1$

$190 \operatorname{INPUT}, T 1(I), T I N(I), \operatorname{TOUT}(I), R I(I), R 3(I)$

200 DO $I I=2, N$

$210 T 1(1)=T 1(1)$

$220 \operatorname{TIN}(1)=\operatorname{TIN}(1)$

230 TOUT $(I)=\operatorname{TOUT}(1)$

$240 R 1(I)=R 1(1)$

$2501 R 3(1)=R 3(1)$

260 PRINT, "INPUT CONSTANTS $\mathrm{Cl}+\mathrm{C} 2+\mathrm{C} 3+\mathrm{H}+\mathrm{K}+\mathrm{S}^{-}$

$270 \quad I=1$

280 INPUT,CI(I),C2(I),C3(I),H(I),K(I),S(I)

290 D० $2 I=2, N$

$300 \mathrm{Cl}(\mathrm{I})=\mathrm{Cl}_{1}(1)$

$310 \mathrm{C2}(\mathrm{I})=\mathrm{C} 2(1)$

$320 \mathrm{C} 3(1)=\mathrm{C} 3(1)$

$330 \mathrm{H}(I)=\mathrm{H}(1)$

$340 K(1)=K(1)$

$350 \approx S(1)=S(1)$

360 PRINT, - INPUT T2*

370 DO $3 I=1, N$

3803 INPUT, TR(I)

390 DO $12 \quad I=1, N$

$400 \quad B(I)=R I(I)=C I(I)$

$410 E(I)=(3.2 *(10 * 7) * C 2(I) * K(I) *(\operatorname{TIN}(I)-T$ TUT $(I))) / S(I)$

$420 F(I)=(R 3(I) * C 3(I) * K(I) *(T I N(I)-T O U T(I))) / H(I)$

$430 \mathrm{DELX}(I)=\operatorname{SQRT}((E(I)+F(I) * A L O G((T I(I)-T I N(I)) /(T 2(I)-\operatorname{TIN}(I)$

$440 \&))) /(D(I) *(T 1(I)-T 2(I))))$

$450 \mathrm{CT}(I)=(D(I) * \operatorname{DELX}(I))+E(I) /(\operatorname{DELX}(I) *(\operatorname{TI}(I)-T 2(I)))+(F(I) *$

460 \&ALOG( $(T I(I)-\operatorname{TIN}(I)) /(T 2(I)-T I N(I)))) /(B D X X(I) *(T I(I)-T 2$

$470 \&(I)))$

48012 CONTINUE

490 PRINT 15

50015 FERMAT ( $15 X, 2 H D, 14 X, 2 H E, 14 X, 1 \mathrm{HF}$ )

510 DO $5 \quad I=1, N$

5205 PRINT, D (I ),E(I),F(I)

5306 FORMAT $(1 X, 3(1 \mathrm{PE} 16 \cdot 7))$

540 PRINT 7

5507 FORMAT ( $1 \mathrm{X}, 14 \mathrm{X}, 2 \mathrm{HT} 2,14 \mathrm{X}, 4 \mathrm{HDEL} \mathrm{X}, 14 \mathrm{X}, 2 \mathrm{HCT})$

560 DO $8 \quad I=1, N$

5708 PRINT, T2(I),DELX(I),CT(I)

5809 FORMAT $(1 X, 3(1 P E 16 \cdot 7))$

590 STOP

600 END

RUN 


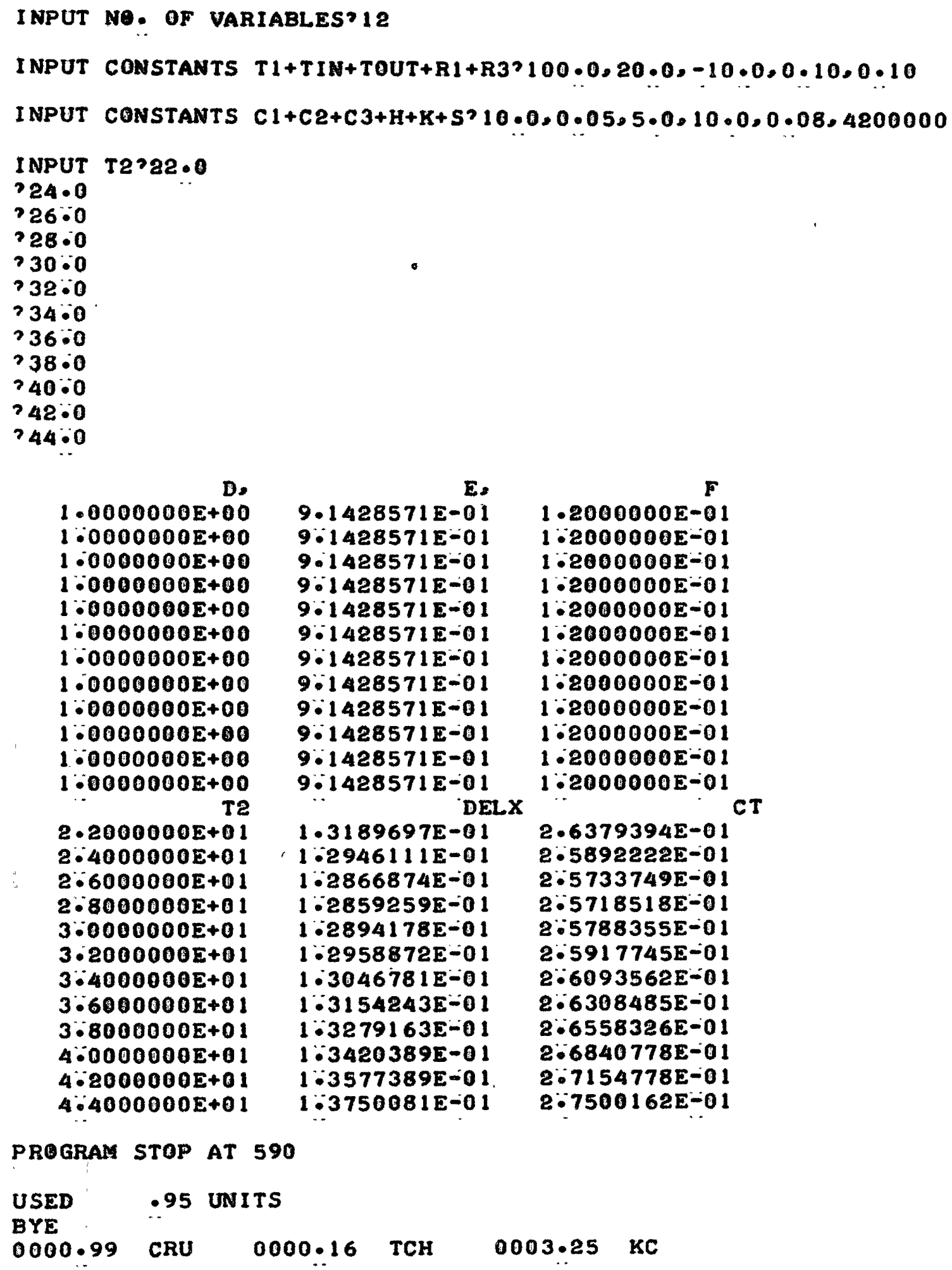




\section{APPENDIX IV}

\section{EXERGY}

We now turn our attention to the concept of exergy or the "specific availability" as it is called in the American literature. It is a concept which has found increasing use in recent years. The word exergy is a term used frequently in the German literature since 1956 to denote the utility of energy. This concept is applicable in the analysis of complex thermodynamic system, and it is a powerful tool in design and optimization studies (thermoeconomic) of such systems. Moreover, it is particularly useful in geothermal engineering.

According to Bodvarsson (8), the exergy of a geothermal fluid (thermal water) is defined as the maximum amount of mechanical work which can be derived from its enthalpy at a given environment temperature. At a fixed environment temperature, exergy is a state variable such as the other thermodynamic properties like enthalpy and entropy.

\section{EXERGY DERIVATION}

The mathematical derivation of exergy is conveniently introduced by the following model. Consider a unit mass of a 
geothermal fluid at a given uniform temperature $\mathrm{T}_{1}$, an enthalpy $i_{1}$, an entropy $S_{1}$; the fluid is enclosed in a reservoir at a fixed depth and constant pressure P. Let the environment be at a lower temperature $\mathrm{T}_{2}$. We will now compute the maximum amount of mechanical work which can be generated from the enthalpy of this mass of fluid by cooling it at a constant pressure to the environmental temperature. In order to find the maximum work, the substance will be connected with an ideal Carnot thermal engine which is capable of operating at a variable input temperature $\mathrm{T}$ and a fixed end temperature $\mathrm{T}_{2}$. On the basis of thermodynamic principles (22), the amount of heat, $d Q$, given up by the substance at a temperature $\mathrm{T}_{1}$ can, in a reversible Carnot cycle, perform a maximum amount of work as the substance is cooled from $T+d T$ to $T$, which is

$$
d E=d Q\left(1-\frac{T_{2}}{T}\right)
$$

and

$$
\mathrm{dQ}=\mathrm{C}_{\mathrm{p}} \mathrm{dT}
$$

is the amount of heat transferred from the substance at constant pressure. Substituting for $d Q$ its value into equation (1), we get

$$
d E=C_{p} d T\left(1-\frac{T_{2}}{T}\right)
$$


or

$$
d E=C_{p} d T-C_{p} \frac{T_{2}}{T} d T
$$

an integration of equation (4) from $T=T_{1}$ to $T=T_{2}$ yields,

$$
E=\int_{T_{1}}^{T_{2}} C_{p} d T-\int_{T_{1}}^{T_{2}} C_{p} \frac{T_{2}}{T} d T
$$

Since for

$$
\Delta i=\int_{T_{1}}^{T_{2}} C_{p} d T
$$

and for a reversible isobaric process

$$
\Delta S=\int_{T_{1}}^{T_{2}} C_{p} \frac{d T}{T}
$$

therefore, by substitution in equation (5), we obtain

$$
E_{12}=\Delta i-T_{2} \Delta S
$$

the total work performed by the ideal engine as the substance is cooled from $T_{1}$ to $T_{2}$. This work is the exergy of the substance, and equation (8) can be expressed as

$$
E_{12}=i_{1}-i_{2}-T_{2}\left(S_{1}-S_{2}\right)
$$

where:

$$
\begin{aligned}
& E_{12}=\text { the exergy by cooling geothermal fluid from } T_{1} \text { to } T_{2} \\
& i_{2}=\text { the enthalpy of the fluid at } T_{2}
\end{aligned}
$$


$S_{2}=$ the entropy of the fluid at $T_{2}$

Since the depth and the pressure of the geothermal mass during the cooling process the kinetic and gravitational energy remain constant. These two types of energy in general have no practical interest in geothermal engineering.

Bodvarsson and Eggers (10) have computed tables for the exergy of thermal water for variable $T_{0}$ (liquid phase reservoir temperature) and for the practical cases of $\mathrm{T}_{2}=30^{\circ} \mathrm{C}, 40^{\circ} \mathrm{C}$, $50^{\circ} \mathrm{C}$ and $100^{\circ} \mathrm{C}$. These values of exergy are convenient for geothermal engineering purposes and also for the design of power cycles in geothermal power plants.

\section{ILLUSTRATIVE EXAMPLE}

The following example will illustrate the application of the exergy concept in geothermal engineering. Consider a geothermal power plant which is operated on the basis of thermal water at a temperature of $T_{0}=260^{\circ} \mathrm{C}$ and environment temperature of $\mathrm{T}_{2}=50^{\circ} \mathrm{C}$. We will compute the exergy for the single and double flash cycles as shown in Figures 3 and 5 of Chapter III. In both cases, the optimum flash temperatures $\mathrm{T}_{1}=155^{\circ} \mathrm{C}$ for single flash cycle and $\left(T_{1}\right)_{1}=182^{\circ} \mathrm{C}$ (first stage), $\left(T_{2}\right)_{2}=116^{\circ} \mathrm{C}$ (second stage) of the double flash cycle are selected to maximize 
the work abtained per unit mass of reservoir water. These optimum temperatures are obtained by the analytical method on the basis of first order approximation method considered in Chapter IV. The results for the exergy flux in both cycles are given in Table I and they were obtained by the following procedures:

1. The exergy values of reservoir water and waste flash water are obtained from the exergy tables computed by Bodvarsson and Eggers (10).

2. The exergy of flash steam is determined on the basis of steam tables and i-s diagram and by equations $(3.3)$ and $(3.10)$ considered in Chapter III. The steam is expanded isentropically in an idealized process, that is, $S_{1}=S_{2}$ 。

3. Exergy loss in the cycle is; exergy loss = exergy of reservoir water - (exergy of flash steam + exergy of waste flash water)。

4. The useful work at an efficiency $(\eta=65 \%)$ is computed as such, useful work $=($ exergy of flash steam $)$ $(\eta)$, where the efficiency of the cycle (percent of exergy of reservoir water available) is $\eta_{c}=\frac{\text { exergy of flash steam }}{\text { exergy of reservoir water }} \times 100$. 
PERFORMANCE OF SINGLE AND DOUBLE

FLASH CYCLES

$$
\begin{gathered}
\text { Percent of } \\
\text { exergy of } \\
\text { reservoir water }
\end{gathered}
$$

(1) Temperature of reservoir water, $\mathrm{T}_{\mathrm{O}} 260^{\circ} \mathrm{C}$

(2) Environment (condensing) tem-

perature, $\mathrm{T}_{\mathrm{e}} \quad 50^{\circ} \mathrm{C}$

(3) Exergy of reservoir water $60.3 \frac{\mathrm{kwh}}{\mathrm{mt}}$

Optimal Sixigle Flash Cycle

(4) Flash temperature, $\mathrm{T}_{1} \quad 155^{\circ} \mathrm{C}$

(5) Exergy of flash steam, viz.

theoretical work of cycle

$38.2 \frac{\mathrm{kwh}}{\mathrm{mt}} \quad 63.3$

(6) Exergy of waste flash water

$16.8 \quad 27.8$

(7) Exergy loss in cycle

5.3

8.7

(8) Useful work at a mechanical

efficiency of $65 \%$

$24.8 \quad 41.4$

Optima1 Double Flash Cycle

(9) Flash temperatures, $\left(\mathrm{T}_{1}\right)_{1}$ $\left(\mathrm{T}_{2}\right)_{1}$

$182^{\circ} \mathrm{C}$

$116^{\circ} \mathrm{C}$

(10) Exergy of flash steam from both

stages, viz. theoretical work

of cycle

$47.5 \frac{\mathrm{kwh}}{\mathrm{mt}} \quad 77.6$

(11) Exergy of waste flash water

from second stage

7.1

11.7

(12) Exergy loss in cycle

$5.7 \quad 9.4$

(13) Useful work at a mechanical efficiency of $65 \%$

30.875

51.2 
Table I shows that the single flash cycle theoretically utilizes 63.3 percent of the exergy available, indicating a good efficiency. The double flash cycle reaches a figure of 77.6 percent which is an increase by approximately 24.3 percent. The improvement in efficiency for each additional flash stage decreases with increasing number of stages. 